\title{
Olorinab (APD371), a peripherally acting, highly selective, full agonist of the cannabinoid receptor 2 , reduces colitis-induced acute and chronic visceral hypersensitivity in rodents
}

Joel Castro ${ }^{a, b, c}$, Sonia Garcia-Caraballo ${ }^{a, b, c}$, Jessica Maddern ${ }^{a, b, c}$, Gudrun Schober $^{a, b, c}$, Amanda Lumsden ${ }^{a, b}$, Andrea Harrington ${ }^{a, b, c}$, Shirdi Schmiel ${ }^{d}$, Beatriz Lindstrom ${ }^{d}$, John Adams ${ }^{d}$, Stuart M. Brierley ${ }^{a, b, c, *}$

\begin{abstract}
Abdominal pain is a key symptom of inflammatory bowel disease and irritable bowel syndrome, for which there are inadequate therapeutic options. We tested whether olorinab-a highly selective, full agonist of the cannabinoid receptor $2\left(\mathrm{CB}_{2}\right)$-reduced visceral hypersensitivity in models of colitis and chronic visceral hypersensitivity $(\mathrm{CVH})$. In rodents, colitis was induced by intrarectal administration of nitrobenzene sulfonic acid derivatives. Control or colitis animals were administered vehicle or olorinab $(3$ or 30 $\mathrm{mg} / \mathrm{kg}$ ) twice daily by oral gavage for 5 days, starting 1 day before colitis induction. Chronic visceral hypersensitivity mice were administered olorinab $(1,3,10$, or $30 \mathrm{mg} / \mathrm{kg})$ twice daily by oral gavage for 5 days, starting 24 days after colitis induction. Visceral mechanosensitivity was assessed in vivo by quantifying visceromotor responses (VMRs) to colorectal distension. Ex vivo afferent recordings determined colonic nociceptor firing evoked by mechanical stimuli. Colitis and $\mathrm{CVH}$ animals displayed significantly elevated VMRs to colorectal distension and colonic nociceptor hypersensitivity. Olorinab treatment significantly reduced VMRs to control levels in colitis and CVH animals. In addition, olorinab reduced nociceptor hypersensitivity in colitis and CVH states in a concentration- and $\mathrm{CB}_{2}$-dependent manner. By contrast, olorinab did not alter VMRs nor nociceptor responsiveness in control animals. Cannabinoid receptor 2 mRNA was detected in colonic tissue, particularly within epithelial cells, and dorsal root ganglia, with no significant differences between healthy, colitis, and $\mathrm{CVH}$ states. These results demonstrate that olorinab reduces visceral hypersensitivity through $\mathrm{CB}_{2}$ agonism in animal models, suggesting that olorinab may provide a novel therapy for inflammatory bowel disease- and irritable bowel syndrome-associated abdominal pain.
\end{abstract}

Keywords: Nociceptors, Visceral hypersensitivity, Colon, Inflammatory bowel disease, Irritable bowel syndrome, Abdominal pain, Cannabinoid receptor 2, Cannabinoid receptor agonists, Visceral pain, Olorinab, Colitis, Colonic nociception, Visceral afferents

\section{Introduction}

Inflammatory bowel diseases (IBDs), including Crohn disease and ulcerative colitis, are chronic relapsing gastrointestinal disorders with increasing prevalence worldwide. ${ }^{48}$ Approximately $70 \%$ of

\footnotetext{
Sponsorships or competing interests that may be relevant to content are disclosed at the end of this article.

a Visceral Pain Research Group, College of Medicine and Public Health, Flinders Health and Medical Research Institute (FHMRI), Flinders University, Bedford Park, South Australia, Australia, ${ }^{b}$ Hopwood Centre for Neurobiology, Lifelong Health Theme, South Australian Health and Medical Research Institute (SAHMRI), North Terrace, Adelaide, South Australia, Australia, ${ }^{C}$ Discipline of Medicine, University of Adelaide, North Terrace, Adelaide, South Australia, Australia, ${ }^{d}$ Arena Pharmaceuticals, Inc, San Diego, CA, United States

${ }^{*}$ Corresponding author. Address: Visceral Pain Research Group, Level 7, SAHMRI, North Terrace, Adelaide, South Australia 5000, Australia. Tel.: +61 881284848. E-mail address: stuart.brierley@flinders.edu.au (S.M. Brierley).

PAIN 163 (2022) e72-e86

Copyright (C) 2021 The Author(s). Published by Wolters Kluwer Health, Inc. on behalf of the International Association for the Study of Pain. This is an open access article distributed under the terms of the Creative Commons Attribution-Non CommercialNo Derivatives License 4.0 (CCBY-NC-ND), where it is permissible to download and share the work provided it is properly cited. The work cannot be changed in any way or used commercially without permission from the journal.

http://dx.doi.org/10.1097/j.pain.0000000000002314
}

patients with IBD experience abdominal pain throughout their disease, and $\sim 50 \%$ experience chronic pain for $\geq 5$ years, profoundly impacting their quality of life. ${ }^{63}$ Irritable bowel syndrome (IBS) is a functional gastrointestinal disorder characterized by recurrent abdominal pain and altered bowel habits (eg, constipation, diarrhea, or both). ${ }^{42,44}$ More than $90 \%$ of patients experience abdominal pain at least weekly ${ }^{3}$; of all IBS symptoms, abdominal pain most severely disrupts quality of life $e^{9,59}$ and is associated with illness severity. ${ }^{56}$ Pain management is imperative in the care of patients with IBD or IBS, underscoring the need for therapies that specifically target abdominal pain.

Activation of colon-innervating spinal sensory afferents by mechanical and chemical stimuli are key processes contributing to abdominal pain. ${ }^{23,50}$ Inflammatory mediators released during colitis can directly activate and sensitize colon-innervating afferents, resulting in enhanced responsiveness to chemical and mechanical stimuli, known as visceral hypersensitivity. ${ }^{7,23,50}$ These changes in colonic afferent function result in enhanced nociceptive signals sent to the spinal cord. ${ }^{7,23,31}$ Therefore, a key therapeutic strategy for abdominal pain associated with IBD and IBS is preventing or reducing afferent sensitization.

Cannabinoids are an attractive treatment for abdominal pain in IBD and IBS. The crystal structures, activation, and signaling mechanisms of the 2 known cannabinoid receptors, cannabinoid 
receptor $1\left(\mathrm{CB}_{1}\right)$ and $2\left(\mathrm{CB}_{2}\right)$, were recently identified. ${ }^{30,38,40}$ Cannabinoid receptor 1 is widely distributed and highly expressed in the brain, where it mediates the psychoactive effects of cannabis. ${ }^{45,53}$ By contrast, $\mathrm{CB}_{2}$ is mainly expressed in immune cells and peripheral tissues, including the colonic mucosa ${ }^{25,60}$ and enteric nervous system (ENS). ${ }^{20}$ Increased $\mathrm{CB}_{2}$ expression has been demonstrated in preclinical models of gastrointestinal inflammation ${ }^{39,57}$ and gut tissue from humans with $\mathrm{IBD}^{60}$ or IBS. ${ }^{16,19}$ Cannabinoid receptor agonists showed activity in preclinical models of visceral and neuropathic pain, 25,34,36,46 and endocannabinoid-like dietary supplements alleviated abdominal pain and discomfort in a phase $2 \mathrm{~b}$ study in patients with IBS. ${ }^{16}$ However, clinical development of these candidates has been limited, possibly because of psychoactive side effects from a lack of selectivity for $\mathrm{CB}_{2}$ vs $\mathrm{CB}_{1}$ or loss of activity from partial $\mathrm{CB}_{2}$ agonism. ${ }^{2,26}$

Olorinab (APD371) is an oral, peripherally acting visceral analgesic and highly selective full agonist of $\mathrm{CB}_{2} \cdot{ }^{26}$ Its $>1000$-fold functional selectivity for $\mathrm{CB}_{2}$ over $\mathrm{CB}_{1}$ and low brain penetration ${ }^{2,26}$ minimize the risk of psychoactive effects. Olorinab activated endogenous $\mathrm{CB}_{2}$ in primary rat splenocytes, human $\mathrm{HL}-60$ cells, and primary human $B$ cells and demonstrated antinociceptive efficacy in preclinical models of chronic pain. ${ }^{2,26}$ In a phase 2 a study in patients with quiescent to mildly active Crohn disease, olorinab was well tolerated and improved abdominal pain. ${ }^{61}$ Based on these findings, we assessed the activity of olorinab in reducing visceral hypersensitivity in rodent models of IBD and IBS.

\section{Methods}

\subsection{Animal studies}

All experiments were performed in accordance with the guidelines of the Animal Ethics Committees of the South Australian Health and Medical Research Institute and Flinders University (ethics project SAM276). Male C57BL/6J mice and Sprague-Dawley rats were used in all experiments. Mice and rats were sourced from the specific and opportunistic pathogen-free facility at the South Australian Health and Medical Research Institute Animal Bioresources. The facility is accredited by the Office of the Gene Technology Regulator and as a physical containment level 2 facility (license number, cert 3767). The facility also has approval to breed and rederive lines. Mice were originally purchased from The Jackson Laboratory (stock number, 000664; breeding barn MP14; Bar Harbor, ME). Rats were originally purchased from Charles River Laboratories (strain code, 400; Wilmington, MA). Mice or rats were group housed (maximum 5 per cage) within individual ventilated cages, which were filled with coarse chip dust-free aspen bedding (PuraChips, Coarse Grade; PuraBed, Niederglatt, Switzerland). Cages were stored on individual ventilated cage racks within temperature-controlled housing rooms $\left(22^{\circ} \mathrm{C}\right.$ with a 12 -hour light and 12-hour dark cycle). Mice and rats had free access to LabDiet JL Rat and Mouse/Auto6F chow (St. Louis, MO) and autoclaved reverse osmosis purified water. The minimum number of animals needed, without impacting data significance, was obtained using G*Power software and was based on our historical data. A power value of 0.80 and an alpha error probability of 0.05 were used to calculate the group's size.

\subsubsection{Animal models of colitis (inflammatory bowel disease-like model)}

Colitis was induced by administration of trinitrobenzene sulfonic acid (TNBS; 1 M solution, Cat\# 92822; Sigma-Aldrich, St. Louis,
MO) or 2,4-dinitrobenzene sulfonic acid (DNBS; Cat\# 556971; Sigma-Aldrich) as described previously. ${ }^{1,24,31,32}$ Briefly, 13week-old male C57BL/6J mice and 6- to 7-week-old male Sprague-Dawley rats were fasted overnight with access to $5 \%$ glucose solution. After the fasting period, isofluraneanaesthetized animals were administered an intracolonic enema of DNBS (6.5 mg in 30\% ethanol; total volume of $0.1 \mathrm{~mL}$ ) for mice and TNBS (12 mg in 35\% ethanol; total volume of $0.3 \mathrm{~mL}$ ) for rats. Animals were then individually housed with unlimited access to soaked food and 5\% glucose solution and were subsequently observed daily for changes in body weight, physical appearance, and behavior.

\subsubsection{Mouse model of chronic visceral hypersensitivity (irritable bowel syndrome-like model)}

Chronic visceral hypersensitivity $(\mathrm{CVH})$ induction was performed as previously described. ${ }^{15,24,31,51}$ Briefly, 10- to 11-week-old male C57BL/6J mice were fasted overnight with access to 5\% glucose solution before administration of an intracolonic enema of DNBS (6.5 mg in 30\% ethanol; total volume of $0.1 \mathrm{~mL}$ ) under isoflurane anesthesia. After DNBS administration, animals were housed individually and monitored daily for changes in body weight, physical appearance, and behavior. Chronic visceral hypersensitivity was assessed 28 days after DNBS administration. Male littermates were used as healthy control animals.

\subsubsection{Olorinab treatment}

Olorinab doses were selected based on the pharmacokinetic profile of the compound in rats and efficacious doses in other preclinical models of pain. Accordingly, our initial in vivo visceromotor response (VMR) studies were performed in rats. Healthy control or colitis rats were orally administered either vehicle control ( $0.5 \%$ methylcellulose) or olorinab ( 3 or $30 \mathrm{mg} / \mathrm{kg}$ ) twice daily (BID) by oral gavage for 5 days starting 1 day before DNBS or TNBS administration (Fig. 1A). Based on our initial findings in rats, we expanded the study to $\mathrm{CVH}$ mice and used 4 doses of olorinab. For the $\mathrm{CVH}$ studies, mice were orally administered either vehicle control ( $0.5 \%$ methylcellulose) or olorinab (1, 3, 10, or $30 \mathrm{mg} / \mathrm{kg}$ ) BID by oral gavage for 5 days starting at 24 days after DNBS administration (Fig. 1B).

\subsection{In vivo visceral pain assessment: visceromotor response to colorectal distension}

The VMR is a nociceptive brainstem reflex consisting of the contraction of the abdominal muscles in response to noxious distension of the colorectum. ${ }^{47}$ We measured the VMRs to CRD as an objective measure of visceral sensitivity in fully conscious animals. ${ }^{11,12,15,24,35,51}$ These studies were performed in healthy, colitis, and $\mathrm{CVH}$ animals.

\subsubsection{Surgical implantation of electrodes}

The VMR was assessed by electromyography (EMG) to quantify abdominal muscle contractions in response to non-noxious and noxious CRD as previously published. ${ }^{12,24,35,51}$ We performed these studies in both rats (healthy and colitis) and mice (healthy and $\mathrm{CVH}$ ). Briefly, 3 days before VMR assessment, rats and mice were anesthetized with isoflurane, and a $1 \mathrm{~cm}$ incision was made just superior to the right inguinal ligament, exposing the external oblique abdominal muscle. Two polytetrafluoroethylene-coated stainless-steel wires (Advent Research Materials Ltd, Witney, 


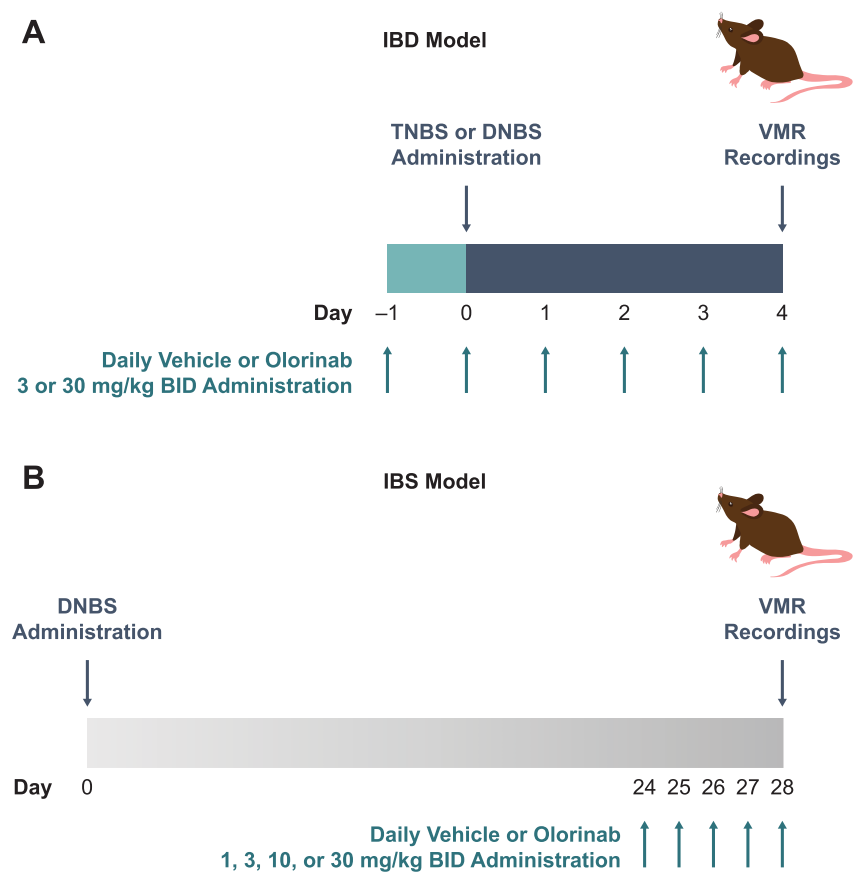

Figure 1. Study design schematic: Overview of the timing of colitis induction with intracolonic TNBS or DNBS administration, oral administration of olorinab or vehicle, and VMR recordings are outlined for (A) IBD (colitis) and (B) IBS (CVH) rodent models. BID, twice daily; CVH, chronic visceral hypersensitivity; DNBS, 2,4dinitrobenzene sulfonic acid; IBD, inflammatory bowel disease; IBS, irritable bowel syndrome; TNBS, trinitrobenzene sulfonic acid; VMR, visceromotor response.

United Kingdom) were sutured into the muscle approximately $5 \mathrm{~mm}$ apart. The electrodes were tunneled subcutaneously and exteriorized at the base of the neck for future access. All rats and mice received prophylactic antibiotics (Baytril [enrofloxacin], Bayer AG; 5 mg/kg subcutaneously) and pain relief (buprenorphine $0.05 \mathrm{mg} / \mathrm{kg}$ subcutaneously). After surgery, animals were single housed to protect the EMG electrodes.

\subsubsection{Assessing visceromotor response to colorectal distension}

On the day of VMR assessment, rats and mice were briefly sedated with isoflurane and received a $500 \mu \mathrm{L}$ saline enema to remove any fecal pellets in the distal colon. A lubricated, latex balloon $(4.0 \mathrm{~cm}$ in length for rat studies, $2.5 \mathrm{~cm}$ in length for mouse studies) was gently passed through the anus and inserted up to $0.5 \mathrm{~cm}$ proximal to the anal verge. Once in position, the balloon catheter was secured to the base of the tail and connected to a barostat (ISOBAR-3, G\&J Electronics Inc, Toronto, Canada) for pressure-controlled rapid inflation. Animals were then transferred to a restrainer with dorsal access, and the EMG electrodes were relayed to a data acquisition system.

Rats and mice were allowed to regain consciousness for at least 10 minutes (mean, 29 minutes; range, 13-37 minutes) before the distension sequence was initiated. Distensions were applied by the barostat in a pressure-controlled fashion, ranging from the non-noxious to the noxious range $(20,40,50,60,70$, and $80 \mathrm{~mm} \mathrm{Hg}$ of 20 seconds in duration with 4-minute intervals between consecutive distensions). The corresponding EMG signal was recorded (NL100AK AC Preamplifer headstage; Digitimer Ltd, Welwyn Garden City, United Kingdom), amplified (gain 2k; NL104A AC Preamplifier; Digitimer Ltd), filtered (bandpass 50-5000 Hz, NL125/126 Band Pass Filter; Digitimer Ltd), digitized (CED Micro1401; Cambridge Electronic Design Ltd, Cambridge, United Kingdom), and stored for analysis.

\subsubsection{Colonic compliance}

Immediately after VMR assessment, the balloon was manually inflated with known volumes of air $(0.25,0.5,0.75,1.0,1.25$, and $1.5 \mathrm{~mL}$ for rat studies and 40, 80, 120, 160, and $200 \mu \mathrm{L}$ for mouse studies), and the corresponding intracolonic pressure was recorded to construct volume-pressure curves as a measure of colonic compliance. ${ }^{11,12,15,24,35}$

\subsubsection{Visceromotor response statistical analysis}

The analog EMG signal obtained from the VMR recordings was rectified and integrated. To quantify the magnitude of the VMR at each distension pressure, the area under the curve (AUC) during the distension (20 seconds) was corrected for the baseline activity (AUC predistension, 20 seconds). ${ }^{11,12,15,24,35}$ Total AUC was quantified by adding the individual AUC at each distension pressure. $^{15,35}$ Data are presented as mean \pm SEM, where $N$ represents the number of animals. Area under the curve data were statistically analyzed by the generalized estimating equations method followed by a least significant difference (LSD) post hoc test when appropriate using IBM SPSS Statistics 23.0. Total AUC data were analyzed using unpaired 2-tailed $t$ tests (for differences between 2 groups) or one-way analysis of variance (ANOVA) with post hoc analysis conducted with the Tukey multiple comparisons test (for differences between more than 2 groups). Analysis and figures were prepared using GraphPad Prism version 7.0. Differences were considered significant at $P<0.05$.

\subsection{Ex vivo mouse colonic primary afferent preparation recording}

Single-unit extracellular recordings from splanchnic colonic afferent nerves were made from healthy, colitis (IBD-like), and $\mathrm{CVH}$ (IBS-like) mice as previously described. ${ }^{6,14,31}$ The colon (5-6 cm) and mesentery (containing the lumbar colonic nerves) 
were removed intact, along with either the attached neurovascular bundle containing the inferior mesenteric ganglion and splanchnic nerve. The tissue was transferred to ice-cold Krebs solution, and, following further dissection, the distal colon and rectum were opened longitudinally along the antimesenteric border to orientate lumbar colonic insertions to lie along the edge of the open preparation. The tissue was pinned flat, mucosal side up, in a specialized organ bath consisting of 2 adjacent compartments generated from clear acrylic (Danz Instrument Service, Adelaide, South Australia, Australia), the floors of which were lined with SYLGARD 184 (Dow Corning Corp., Midland, MI). The neurovascular bundle containing the splanchnic nerve was extended from the tissue compartment into the recording compartment where they were laid onto a mirror. A movable wall with a small "mouse hole" was lowered into position to allow passage of the nerves and the recording chamber filled with paraffin oil. The colonic compartment was superfused with a modified Krebs solution (117.9 mM NaCl, $4.7 \mathrm{mM} \mathrm{KCl,} 25 \mathrm{mM} \mathrm{NaHCO}_{3}, 1.3 \mathrm{mM}$ $\mathrm{NaH}_{2} \mathrm{PO}_{4}, 1.2 \mathrm{mM} \mathrm{MgSO}_{4}\left(\mathrm{H}_{2} \mathrm{O}\right)_{7}, 2.5 \mathrm{mM} \mathrm{CaCl}_{2}, 11.1 \mathrm{mM}$ Dglucose), bubbled with carbogen $\left(95 \% \mathrm{O}_{2}\right.$ and $\left.5 \% \mathrm{CO}_{2}\right)$ at a temperature of $34^{\circ} \mathrm{C}$. All preparations contained the L-type calcium channel antagonist nifedipine $(1 \mu \mathrm{M})$ to suppress smooth muscle activity and the prostaglandin synthesis inhibitor indomethacin $(3 \mu \mathrm{M})$ to suppress potential inhibitory actions of endogenous prostaglandins. Under a dissecting microscope, the splanchnic nerve was dissected away from the neurovascular bundle and the nerve sheath surrounding the splanchnic nerve. Using fine forceps, the nerve trunk was teased apart into 6 to 10 bundles, which were individually placed onto a platinum recording electrode. A platinum reference electrode rested on the mirror in a small pool of Krebs solution adjacent to the recording electrode.

\subsubsection{Characterization of colonic afferent properties}

Receptive fields were identified by systematically stroking the mucosal surface and mesenteric attachment with a stiff brush. Once identified, receptive fields were assessed with 3 distinct stimuli to enable classification: focal compression of the receptive field with calibrated von Frey hairs (vfh; 2000 mg; each force applied 3 times for a period of 3 seconds with a 10-second interval between each application), mucosal stroking with calibrated vfh (10 mg force applied 10 times), and circular stretch (5 $\mathrm{g}$ for a period of 1 minute). Stretch was applied using a claw made from bent dissection pins attached to the tissue adjacent to the afferent receptive field and connected to a cantilever system through thread. Weights were applied to the opposite side of the cantilever system to initiate graded colonic stretch. Only circular, and not longitudinal, stretch was tested in this study. Categorization of afferent properties was accorded based on previously published classifications $4,6,31,35,49$ and consisted of colonic nociceptors responding to focal compression and high-intensity stretch ( $\geq 7 \mathrm{~g}$ ), but not low-intensity stroking (10 mg) nor lowintensity circular stretch $(\leq 5 \mathrm{~g})$.

For colonic nociceptor recordings from healthy, colitis, and $\mathrm{CVH}$ mice, after the baseline firing rate was recorded in response to mechanical stimulation with vfh $(2 \mathrm{~g})$, olorinab $(0.01,0.1,1.0$, or $10 \mu \mathrm{M}$ ) and/or a $\mathrm{CB}_{2}$ antagonist (SR144528; $1.0 \mu \mathrm{M}$ SR144528 alone or $1.0 \mu \mathrm{M}$ SR144528 plus $1.0 \mu \mathrm{M}$ olorinab) were applied for 10 minutes through a small metal ring to the surface of the mucosal epithelium of colonic nociceptors, as previously described. ${ }^{12-15,24,35,49}$ Measurement of the firing rate in response to mechanical stimulation with vfh $(2 \mathrm{~g})$ was repeated after drug application.

\subsubsection{Colonic nociceptor statistical analysis}

Electrical signals generated by nerve fibers were amplified, filtered, digitized, and stored as described previously. Action potentials were analyzed off-line using the Spike2 version 5.21 wavemark function and discriminated as single units on the basis of distinguishable waveform, amplitude, and duration. Data are presented as spikes/second or total number of action potentials per response. Data are expressed as mean with the SEM, and $n$ is the number of afferents. Data were analyzed using one-way ANOVA followed by Bonferroni post hoc tests to determine significance. Differences were considered significant at $P<0.05$.

\subsection{Quantitative reverse transcription polymerase chain reaction studies}

\subsubsection{Isolation of mouse colonic tissue and dorsal root ganglia}

Healthy, colitis, or $\mathrm{CVH}$ mice ( $\mathrm{N}=2-6$ per group) were humanely killed using carbon dioxide asphyxiation followed by cardiac perfusion, and tissues were quickly isolated. From each group, 2 $\mathrm{cm}$ of the distal colon was isolated and placed in ice-cold phosphate-buffered saline (PBS). The colon was flushed with icecold PBS to remove remaining fecal pellets and was cut longitudinally to collect the mucosal layer by carefully scraping the top layer under a dissecting microscope. The mucosal layer and the remaining tissue (muscle + ENS) were separated into different tubes and snap-frozen in liquid nitrogen. Dorsal root ganglia (DRG) were isolated concurrently with the colon to minimize the isolation time and ensure high messenger RNA (mRNA) integrity. Colon-innervating thoracolumbar (TL; T10-L1) and lumbosacral (LS; L6-S1) DRG were isolated using the last rib (T13) as a location marker and stored in 2 separate tubes. TL and LS DRG were snap-frozen in liquid nitrogen. All tissues were stored at $-80^{\circ} \mathrm{C}$ until use as described previously. ${ }^{15,33}$

\subsubsection{Sample preparation}

RNA from mouse colonic tissue was isolated using the PureLink RNA Mini Kit (Invitrogen, Carlsbad, CA) and from mouse DRG using the PureLink RNA Micro Kit (Invitrogen) according to the manufacturer's instructions without modifications as described previously. ${ }^{13,15,18}$ All samples underwent an on-column DNase treatment with the PureLink DNase Set (Invitrogen). The elution volumes were $60 \mu \mathrm{L}$ for mouse colonic tissue RNA and $20 \mu \mathrm{L}$ for mouse DRG RNA. RNA was aliquoted and stored at $-80^{\circ} \mathrm{C}$ until use. RNA quality was assessed using the 2100 Bioanalyzer Instrument (Agilent Technologies, Inc, Santa Clara, CA) or the 2200 TapeStation System (Agilent Technologies, Inc). All samples had an RNA integrity number of 6.5 or higher.

\subsubsection{Quantitative reverse transcription polymerase chain reaction and probes}

Quantitative reverse transcription polymerase chain reaction (qRTPCR) was performed using the EXPRESS One-Step Superscript qRT-PCR Kit (Invitrogen) and commercially available hydrolysis probes (TaqMan, Thermo Fisher Scientific). Rodent $\mathrm{CB}_{2}$ genes have 2 distinct promoter regions resulting in differential tissue expression $\left(\mathrm{CB}_{2 \mathrm{~A}}\right.$ and $\left.\mathrm{CB}_{2 \mathrm{~B}}\right){ }^{41}$ Therefore, 3 TaqMan probes were used to measure $\mathrm{CB}_{2}$ expression: $\mathrm{CB}_{2 \mathrm{~A}}$ (Mm00438286_m1 [mouse $\mathrm{Cnr}_{\mathrm{A}}$ exon $1+3]$ ), $C_{2 B}\left(A P E P U Z 6{ }^{64}\right.$ [mouse $C n r 2_{B}$ exon $\left.2+3\right]$ ), and $\mathrm{CB}_{2 \mathrm{~A}+\mathrm{B}}\left(\mathrm{Mm02620087}\right.$ _s1 [detects both mouse $\mathrm{Cnr}{ }_{A}$ and $\mathrm{Cnr}{ }_{B}$ isoforms]). Cannabinoid receptor 1 transcript expression was also 


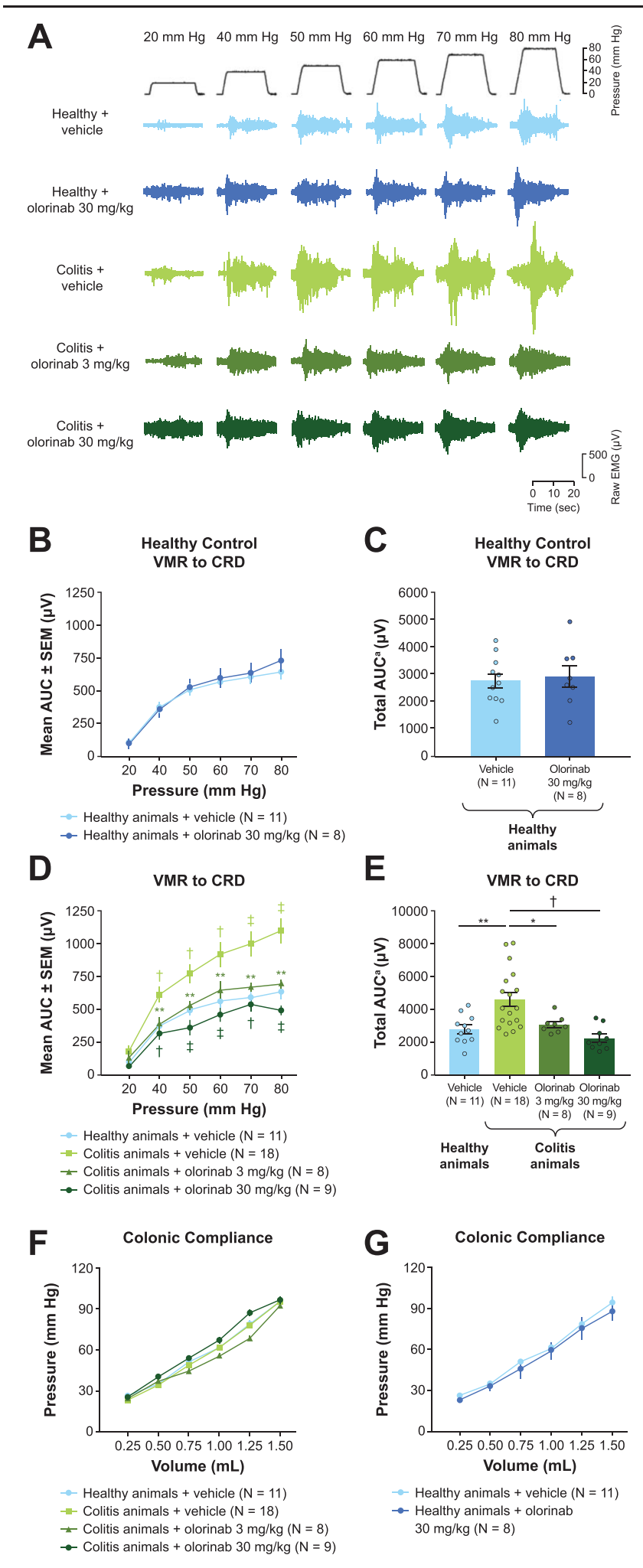

Figure 2. Olorinab reversed colitis-induced hypersensitivity to CRD in colitis animals but had no effect in healthy animals. (A) Representative examples of EMG signals in response to each distension pressure for all animal cohorts. (B) In healthy rats, compared with vehicle treatment, olorinab administration at the highest dose of $30 \mathrm{mg} / \mathrm{kg}$ failed to alter the VMR to CRD. Comparison was not significant based on the generalized estimating equation method followed by the LSD post hoc test $(P>0.05$ ). (C) Total AUC (sum of the AUC obtained at all distension pressures) of the VMR to CRD showed no difference in response between healthy rats treated with vehicle or the highest dose of olorinab (30 $\mathrm{mg} / \mathrm{kg}$ ). Comparison was not significant using a 2-tailed unpaired $t$ test $(P>$ 0.05). (D) Vehicle-treated colitis rats exhibited significantly enhanced VMR to CRD compared with vehicle-treated healthy control rats. Significant increases assessed using mouse (Mm01212171_s1 [mouse Cnr1 exon 2]) $\mathrm{CB}_{1}$ probes. $\beta$-Actin (Mm00607939_s1), peptidylprolyl isomerase A (Mm02342430_g1), and glyceraldehyde-3-phosphate dehydrogenase (Mm99999915_g1) were used as reference genes.

Per reaction, $10 \mu \mathrm{L}$ EXPRESS SuperScript qPCR SuperMix Universal, $1 \mu \mathrm{L}$ TaqMan probe, $0.04 \mu \mathrm{L}$ ROX Reference Dye (25 $\mu \mathrm{M}), 2 \mu \mathrm{L}$ diethylpyrocarbonate-treated water, $2 \mu \mathrm{L}$ EXPRESS SuperScript Mix for One-Step qPCR, and $5 \mu \mathrm{L}$ template RNA were used in all experiments. Fifty nanograms of total mouse colonic RNA per well was used. Because of yield issues during RNA isolation from DRG, some samples could not be used. Therefore, only 25 ng of total mouse DRG RNA per well was used. Twenty-five to $50 \mathrm{ng}$ of RNA is a reasonable amount for the detection of low-expressing targets using this assay. Samples were run in duplicate. PCR runs were performed on a 7500 Fast Real-Time PCR System (Applied Biosystems, Foster City, CA). Results were analyzed using the delta $\mathrm{Ct}$ (cycle threshold) method to calculate relative expression levels: $\mathrm{N}$ $(0)=2^{\text {(Ct [geometric mean of reference genes] }-\mathrm{Ct} \text { [target]) }}$.

\subsubsection{Quantitative reverse transcription polymerase chain reaction statistical analysis}

All qRT-PCR data were plotted as mean \pm SEM. One-way ANOVA followed by the Tukey post hoc test was used to determine statistical significance $(P<0.05)$ between transcript levels within healthy, colitis, and $\mathrm{CVH}$ states. Two-way ANOVA was used when comparing transcript expression levels across states.

\subsection{RNA in situ hybridization}

Healthy, colitis, and $\mathrm{CVH}$ mice ( $\mathrm{N}=6$ per cohort) were humanely killed by overdose of Lethabarb $(0.2 \mathrm{~mL}$ for $30 \mathrm{~g}$ mouse; Virbac, Milperra, NSW, Australia) administered through intraperitoneal injection, 28 days after DNBS administration. Heparinized saline $(0.5 \mathrm{~mL})$ was injected into the left ventricle of the heart, followed by warmed phosphate buffer (0.1 M PB) inserted through a perfusion needle. The right atrium was snipped to allow liquids to exit the circulation. Mice were perfused through a peristaltic pump with $20 \mathrm{~mL}$ of warm $0.1 \mathrm{M} \mathrm{PB}$ followed by $50 \mathrm{~mL}$ of ice-cold $4 \%$ paraformaldehyde (PFA). Two centimeters of the descending colon was flushed with ice-cold 0.1 M PB to remove fecal pellets and was placed in ice-cold 4\% PFA. Using the lowest rib as a

in colitis rats were observed across all distension pressures from $40 \mathrm{~mm} \mathrm{Hg}$. Olorinab treatment of colitis rats with doses of either $3 \mathrm{mg} / \mathrm{kg}$ or $30 \mathrm{mg} / \mathrm{kg}$ significantly reduced VMR to CRD relative to vehicle-treated colitis rats. Comparisons were performed using the generalized estimating equation method followed by the LSD post hoc test. ${ }^{\star \star} P<0.01$; $† P<0.001 ; \ddagger P<$ 0.0001 . (E) Total AUC (sum of the AUC obtained at all distension pressures) of the VMR to CRD shows significantly elevated responses in colitis rats compared with control rats. Olorinab $3 \mathrm{mg} / \mathrm{kg}$ and $30 \mathrm{mg} / \mathrm{kg}$ significantly reduced the total $A \cup C$ of the VMR to CRD relative to vehicle-treated colitis rats. Comparisons were performed using a one-way ANOVA followed by a Tukey multiple comparisons test. ${ }^{\star} P<0.05 ;{ }^{\star *} P<0.01 ;+P<0.001$. (F) No significant changes in colonic compliance were observed between healthy rats treated with vehicle and colitis rats treated with vehicle or olorinab at either dose. (G) No significant changes in colonic compliance were observed between healthy rats treated with vehicle or olorinab $30 \mathrm{mg} / \mathrm{kg}$. All compliance comparisons were performed using the generalized estimating equation method followed by the LSD post hoc test, and results were not significant $(P$ $>0.05)$. Data are presented as mean \pm SEM. AUC was calculated as the difference of area values obtained predistension (20 seconds) minus those obtained during distension (20 seconds). ${ }^{\text {aS }}$ um of the AUC obtained at all distension pressures. ANOVA, analysis of variance; AUC, area under the curve; CRD, colorectal distension; EMG, electromyography; LSD, least squares difference; VMR, visceromotor response. 


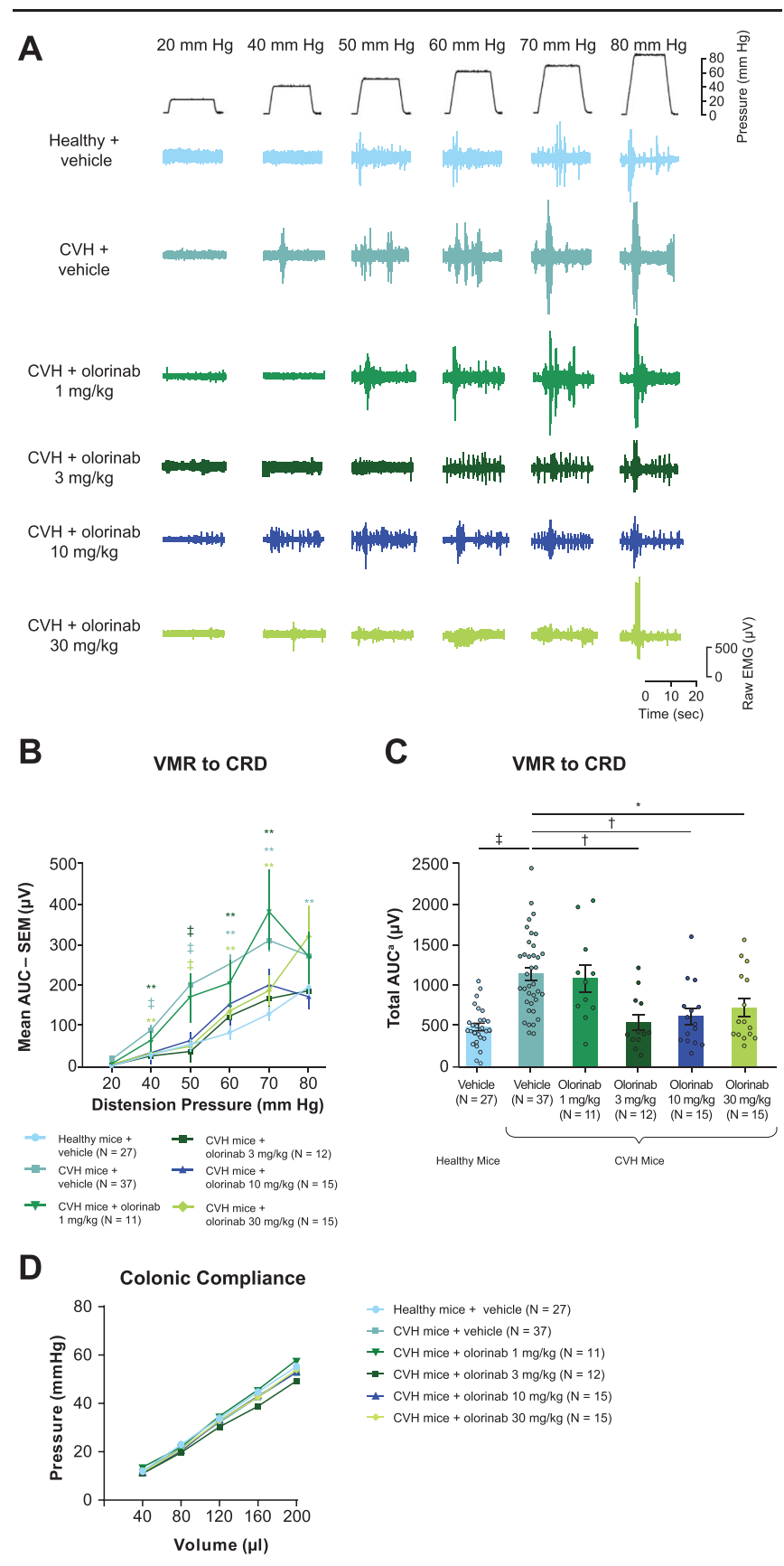

Figure 3. Olorinab reversed hypersensitivity to $\mathrm{CRD}$ in $\mathrm{CVH}$ mice but had no effect in healthy mice. (A) Representative examples of EMG signals in response to each distension pressure for all mouse cohorts. (B) Vehicle-treated $\mathrm{CVH}$ mice exhibited significantly enhanced VMR to CRD compared with vehicle-treated healthy control mice. Significant increases in $\mathrm{CVH}$ mice were observed for distension pressures higher than $40 \mathrm{~mm} \mathrm{Hg}$. Olorinab treatment of CVH mice with doses of $3 \mathrm{mg} / \mathrm{kg}, 10$ $\mathrm{mg} / \mathrm{kg}$, or $30 \mathrm{mg} / \mathrm{kg}$ significantly reduced VMR to CRD relative to vehicle-treated colitis mice. Olorinab $1 \mathrm{mg} / \mathrm{kg}$ was not effective in reducing VMR to $\mathrm{CRD}$ in $\mathrm{CVH}$ mice. Comparisons were performed with generalized estimating equation using an LSD post hoc test. ${ }^{\star \star} P<0.01 ; \ddagger P<0.0001$. (C) Total AUC of the VMR to CRD showed significantly elevated responses in $\mathrm{CVH}$ mice compared with control mice. Olorinab $3 \mathrm{mg} / \mathrm{kg}, 10 \mathrm{mg} / \mathrm{kg}$, and $30 \mathrm{mg} / \mathrm{kg}$ significantly reduced the total AUC of the VMR to CRD relative to vehicle-treated $\mathrm{CVH}$ mice. Comparisons were performed using a one-way ANOVA followed by Tukey post hoc tests. ${ }^{*} P<0.05$; $\dagger P<0.001 ; \ddagger P<0.0001$. (D) No significant changes in colonic compliance were observed between healthy mice treated with vehicle and $\mathrm{CVH}$ mice treated with vehicle or olorinab at all doses. Data are presented as mean \pm SEM. AUC was calculated as the difference of area values obtained predistension (20 seconds)

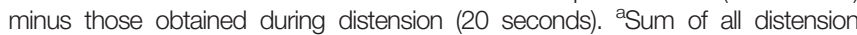
pressures. ANOVA, analysis of variance; AUC, area under the curve; CRD, colorectal distension; $\mathrm{CVH}$, chronic visceral hypersensitivity; EMG, electromyography; LSD, least squares difference; VMR, visceromotor response. marker for T13 and L1 DRG, TLDRG (T9-L1) and LS DRG (L6-S1) were isolated, pooled separately for TL and LS, and placed in icecold 4\% PFA. Spinal cord areas that corresponded to the isolated DRG sections and the entire spleen were also removed and placed in $4 \%$ PFA. All tissues were postfixed in $4 \%$ PFA at $4^{\circ} \mathrm{C}$ for 20 to 24 hours, then transferred to a series of graded sucrose/ 0.1 M PB solutions (10\%, 20\%, and 30\%) each for 24 hours. Tissue was frozen in Optimal Cutting Compound (Tissue-Tek OCT Compound, Sakura Finetek, Alphen aan den Rijn, Netherlands) and stored at $-80^{\circ} \mathrm{C}$ until use. Tissue sections were cut with a cryostat at 10- $\mu \mathrm{m}$ thickness. Sections were mounted in duplicate or triplicate for each sample of colon and DRG, respectively, with a randomly selected sample from each group per slide; some slides also contained a section of spleen (positive control). Slides were air dried at room temperature and washed in $7.4 \mathrm{pH}$ PBS before the in situ hybridization (ISH) staining protocol.

In situ labeling was performed with the RNAscope $2.5 \mathrm{HD}$ Manual Assay BROWN (Advanced Cell Diagnostics, Newark, CA) kit. Briefly, slides were pretreated with $\mathrm{H}_{2} \mathrm{O}_{2}$ solution, washed, and submerged in heated $\left(>96^{\circ} \mathrm{C}\right)$ target retrieval solution for 10 minutes for the colon or 5 minutes for DRG. Slides were dipped in ethanol, air dried, and treated with Protease Plus (Advanced Cell Diagnostics) for 30 minutes, followed by the in situ probes for 2 hours in a $40^{\circ} \mathrm{C}$ prewarmed humidity chamber. RNAscope Probes for $\mathrm{CB}_{2}$ (NM_009924.3), a negative control (dihydrodipicolinate reductase gene [dapB]; EF191515), and a positive control (peptidylprolyl isomerase B gene; NM_011149.2) were used. Sections underwent amplification per the manufacturer's protocol and were counterstained the following day with $25 \%$ hematoxylin solution, Gill No. 1 (Sigma-Aldrich, Saint Louis, MO), dipped in acid alcohol, and incubated in Scott's water bluing agent ( $3.5 \mathrm{~g} / \mathrm{L} \mathrm{NaHCO}{ }_{3}$ and $20 \mathrm{~g} / \mathrm{L}$ $\mathrm{MgSO}_{4}$; chemicals from Sigma-Aldrich). Sections were dehydrated by graded ethanol washes followed by 2 xylene baths, mounted in DPX (Sigma-Aldrich), and dried overnight until imaged. Sections were imaged with a NanoZoomer Digital Slide Scanner (Hamamatsu Photonics, Shizoku, Japan) using $5 \times$ to $40 \times$ objectives, with no modifications made to the images.

\subsubsection{In situ hybridization analysis}

All images were imported into a QuPath image analysis program, allowing the regions of interest (ROls) to be created onto the images covering only the colonic epithelium. The detect positive staining analysis module with standardized settings (downsample factor 2, Gaussian sigma 2, hematoxylin threshold "negative" 1 OD units, DAB threshold "positive" 0.3-0.4 OD units) was then run for each $\mathrm{ROI}$ in each image. This produced measurements for the percentage of the total $\mathrm{ROI}$ stained with "positive pixels." Measurements of percentages of the positive pixel area were collected from 3 to 4 ROls per image and copied to an Excel spreadsheet. After all images were analyzed in this fashion, they were sorted into their experimental groups, and the percentages of the positive pixel area per ROI per section were plotted and analyzed using GraphPad Prism (version 8). Data are plotted as all ROls per section, average area per section, and average area per mouse.

\section{Results}

\subsection{Olorinab decreased colitis-induced acute visceral hypersensitivity}

To determine the potential for olorinab to reduce acute visceral hypersenstivity, we evaluated whether olorinab affected visceral sensitivity to $C R D$ in healthy rats in vivo by measuring the VMR to 


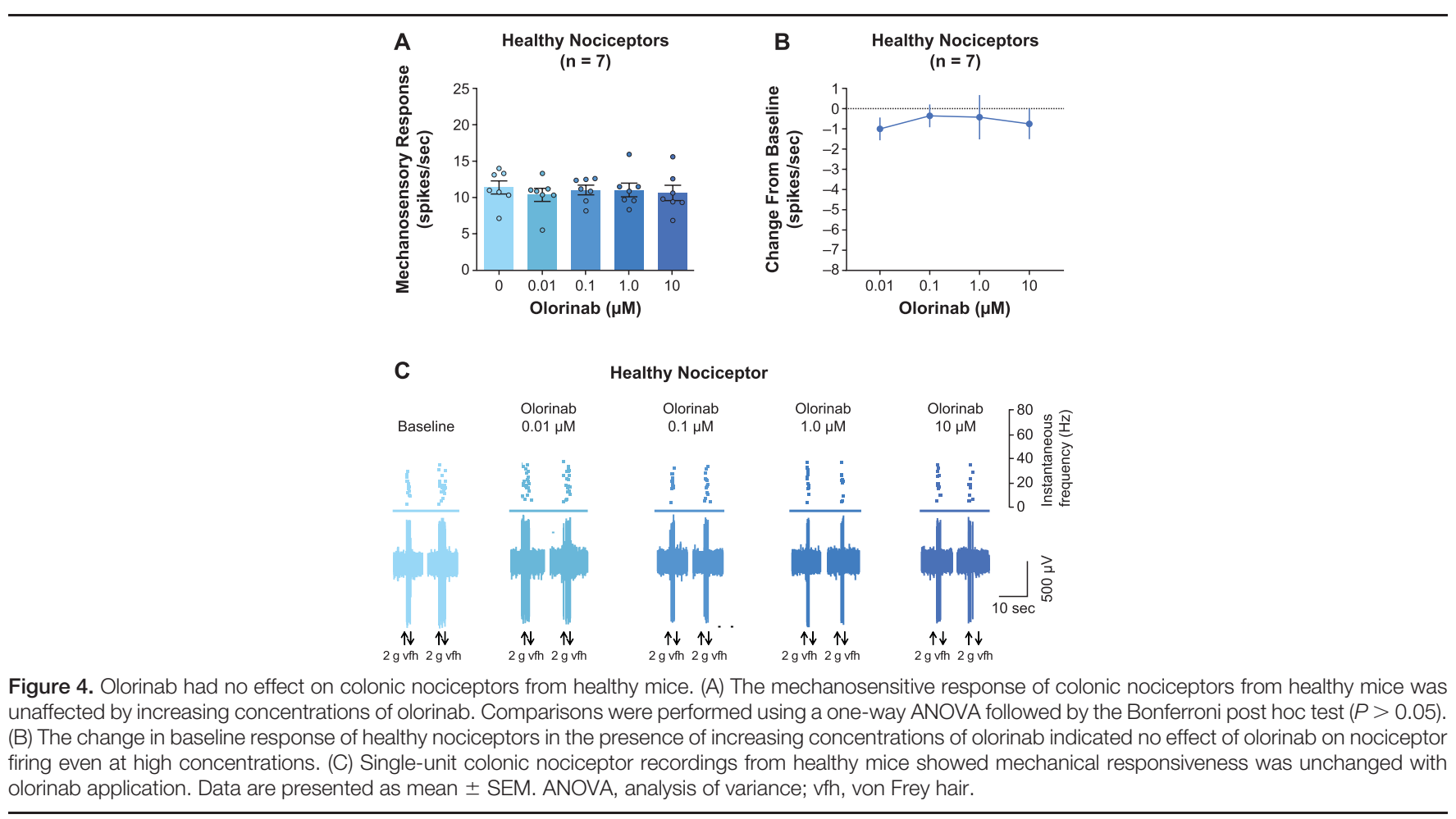

increasing CRD pressures by recording EMG activity from electrodes surgically implanted into the abdominal muscles. The abdominal EMG activity increased in a graded fashion with increasing levels of CRD (Fig. 2A). Olorinab $30 \mathrm{mg} / \mathrm{kg}$, the highest dose tested in this study, had no effect on the VMR to CRD in healthy rats compared with vehicle-treated control animals (Figs. 2A-C).

We and others have previously demonstrated that colitis in mice and rats induces pronounced visceral hypersensitivity to mechanical stimuli. ${ }^{1,7,31,32}$ Here, we repeated those findings and found that rats with active colitis (4 days after colitis induction) displayed pronounced visceral hypersensitivity in vivo. This was indicated by significantly elevated VMR to CRD at pressures from $40 \mathrm{~mm} \mathrm{Hg}$ to $80 \mathrm{~mm} \mathrm{Hg}$ compared with control animals (Figs. 2A, D). We also found that the colitis rats displayed significantly increased total VMRs (combined responses across all distension pressures) compared with control rats (Fig. 2E). We then treated animals with 2 different doses of olorinab ( 3 or $30 \mathrm{mg} / \mathrm{kg}$ ) or vehicle and found that both doses of olorinab significantly reduced the VMR to CRD across distension pressures from $40 \mathrm{~mm} \mathrm{Hg}$ to $80 \mathrm{~mm} \mathrm{Hg}$ compared with vehicle treatment (Figs. $2 \mathrm{~A}, \mathrm{D}, \mathrm{E})$. Olorinab at $3 \mathrm{mg} / \mathrm{kg}$ reduced the VMR to CRD across all distension pressures $(20-80 \mathrm{~mm} \mathrm{Hg}$ ) back to the levels of responsiveness observed in vehicle-treated control animals (Figs. 2D, E), whereas the $30 \mathrm{mg} / \mathrm{kg}$ olorinab dose reduced the VMR to CRD across all distension pressures to below control levels (Figs. 2D, E). Notably, the compliance of the colon was not significantly altered by colitis or by olorinab treatment (Figs. 2F, G), suggesting that changes in the elasticity of the colon did not contribute to these findings, indicating an effect at the level of the colonic afferent endings.

\subsection{Olorinab decreased colitis-induced chronic visceral hypersensitivity}

We have previously demonstrated that after recovery from colitis, mice display pronounced visceral hypersensitivity to mechanical stimuli in the postinflammatory state. 8,12-15,17,24,31,32,35,49 Here, we repeated those findings and found that 28 days after colitis induction, mice displayed $\mathrm{CVH}$ in vivo, as indicated by significantly elevated VMR to $\mathrm{CRD}$, particularly at distension pressures from $40 \mathrm{~mm} \mathrm{Hg}$ to $80 \mathrm{~mm} \mathrm{Hg}$, compared with control mice (Figs. 3A, B). We also found that the CVH mice displayed significantly increased total VMRs compared with control mice (Figs. 3A, C). We then treated mice with 4 different doses of olorinab (1, 3, 10, or $30 \mathrm{mg} / \mathrm{kg}$ ) or vehicle and found that doses of $3 \mathrm{mg} / \mathrm{kg}, 10 \mathrm{mg} / \mathrm{kg}$, or $30 \mathrm{mg} / \mathrm{kg}$ significantly reduced the VMR to $\mathrm{CRD}$ and the total AUC to CRD relative to vehicle-treated colitis mice (Figs. 3A-C). By contrast, olorinab $1 \mathrm{mg} / \mathrm{kg}$ was not effective at reducing the VMR to $\mathrm{CRD}$ in $\mathrm{CVH}$ mice (Figs. $3 \mathrm{~A}-\mathrm{C}$ ). Notably, colonic compliance was unaltered in $\mathrm{CVH}$ mice compared with healthy control mice and was unaltered by olorinab treatment (Fig. 3D), further supporting the hypothesis that the analgesic effect of olorinab occurs at the level of the colonic afferent endings.

\subsection{Olorinab reduced mechanical hypersensitivity of colonic nociceptors from colitis and chronic visceral hypersensitivity mice through a cannabinoid receptor 2-dependent mechanism}

To determine whether olorinab alters colonic sensory function at the afferent level, ex vivo recordings of colonic nociceptors from healthy control, colitis, and CVH mice were assessed. We found that acute application of olorinab $(0.01 \mu \mathrm{M}-10 \mu \mathrm{M})$ to the mucosal surface surrounding the afferent ending had no effect on healthy colonic nociceptor responses to mechanical stimuli (Figs. 4A-C), which was consistent with our in vivo findings of olorinab administered to healthy rats. By contrast, olorinab (0.01 $\mu \mathrm{M}-10 \mu \mathrm{M})$ significantly and dose dependently decreased the activity of colonic nociceptors from colitis mice, with a maximum reduction in response to mechanical stimulation of approximately $50 \%$ at the highest concentration of olorinab tested 
IBD Model

A
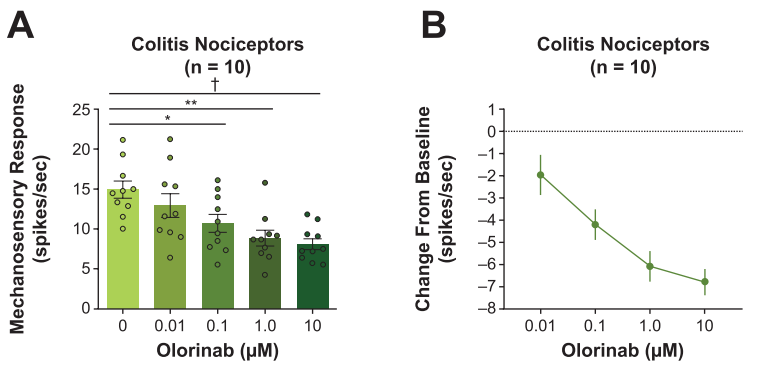

C

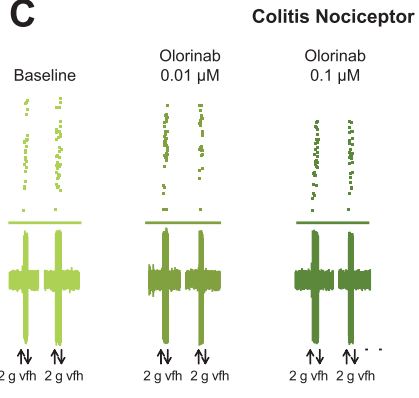

D

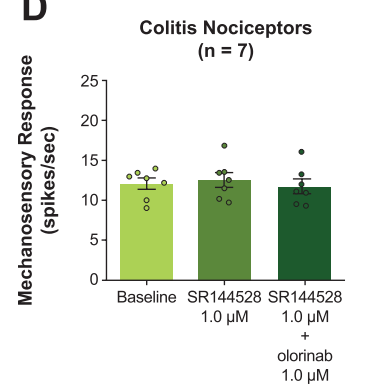

\section{E}

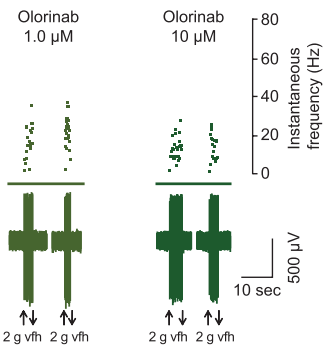

E

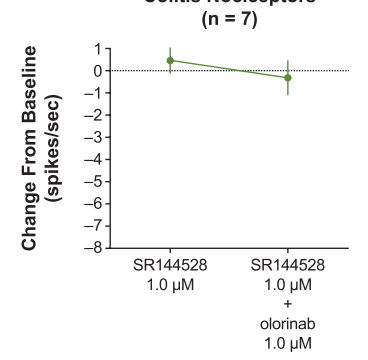

$\mathbf{F}$

Colitis Nociceptor
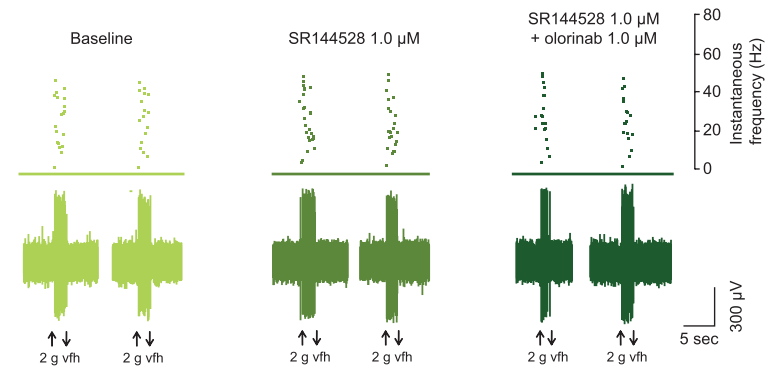

Figure 5. Olorinab dose dependently inhibited colonic nociceptors from colitis mice through a $\mathrm{CB}_{2}$-dependent mechanism. (A) Application of increasing concentrations of olorinab to ex vivo colonic nociceptor endings isolated from colitis mice caused a dose-dependent decrease in action potential firing in response to mechanical stimulation ( $2 \mathrm{~g}$ vfh). Comparisons were performed using a one-way ANOVA followed by the Bonferroni post hoc test $\left({ }^{\star} P<0.05\right.$; ${ }^{* *} P<0.01$; $+P<0.001)$. (B) The change in colitis colonic nociceptor mechanosensitivity induced by olorinab compared with baseline responses indicated a dosedependent decrease in nociceptor firing with increasing concentrations of olorinab. (C) Single-unit colonic nociceptor recordings from colitis mice showed mechanical responsiveness at baseline and dose-dependent inhibition with increasing concentrations of olorinab. (D) Application of the $\mathrm{CB}_{2}$ antagonist SR144528 had no effect on the baseline mechanosensitivity of colitis colonic nociceptors and prevented olorinab-induced inhibition of nociceptor hypersensitivity. Comparisons were performed using a one-way ANOVA followed by the Bonferroni post hoc test $(P>0.05)$. (E) The change in colitis colonic nociceptor mechanosensitivity compared with baseline demonstrated no inhibitory action of olorinab in the presence of the $\mathrm{CB}_{2}$ antagonist. (F) Single-unit colonic nociceptor recordings from colitis mice showed mechanical responsiveness was unchanged with olorinab application in the presence of the $\mathrm{CB}_{2}$ antagonist. Data are presented as mean \pm SEM. ANOVA, analysis of variance; $\mathrm{CB}_{2}$, cannabinoid receptor 2; $\mathrm{IBD}$, inflammatory bowel disease; vfh, von Frey hair.
IBS Model
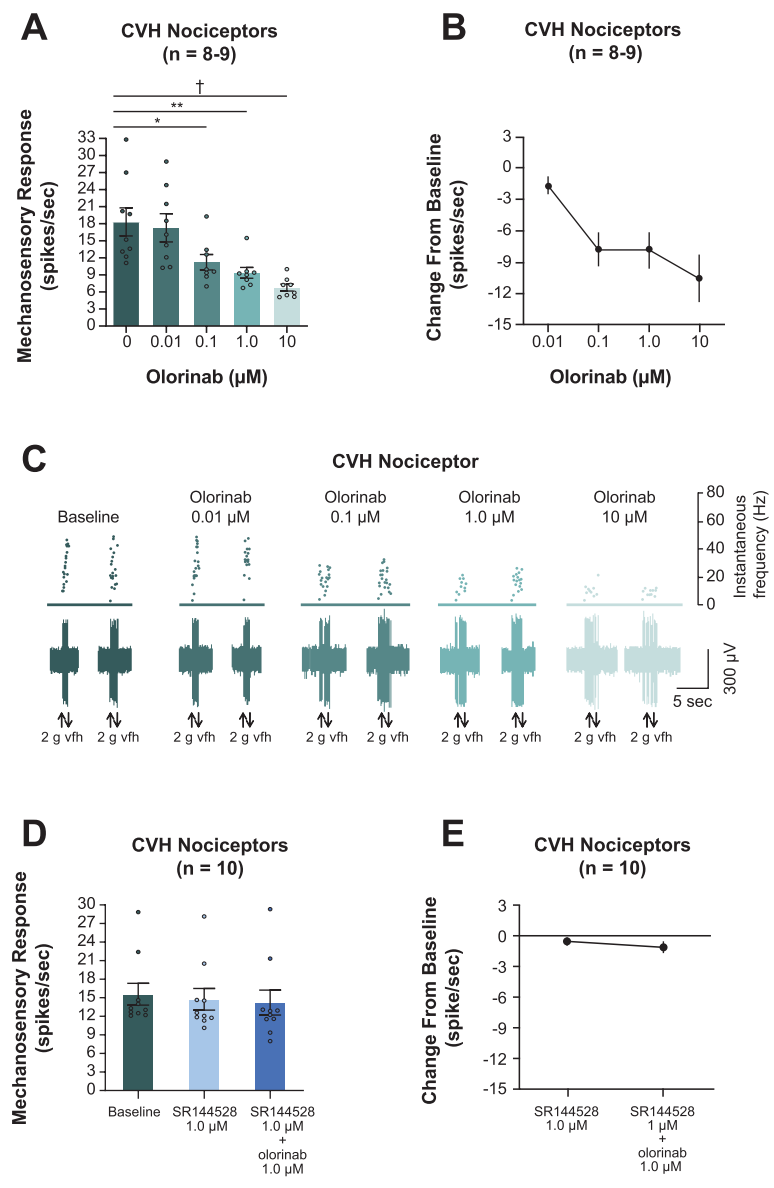

$\mathbf{F}$

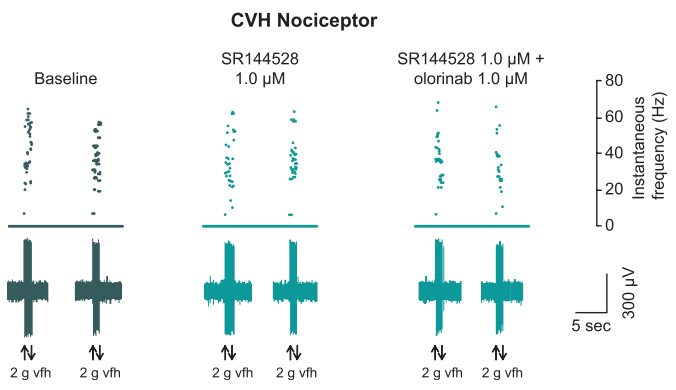

Figure 6. Olorinab dose dependently inhibited colonic nociceptors from $\mathrm{CVH}$ mice through a $\mathrm{CB}_{2}$-dependent mechanism. (A) Ex vivo application of increasing concentrations of olorinab to colonic nociceptor endings isolated from $\mathrm{CVH}$ mice caused a decrease in action potential firing in response to mechanical stimulation ( $2 \mathrm{~g} \mathrm{vfh} ;{ }^{\star} P<0.05,{ }^{\star \star} P<0.01,+P<0.001$ ). (B) The change in $\mathrm{CVH}$ colonic nociceptor mechanosensitivity induced by olorinab compared with baseline responses indicated a dose-dependent decrease in nociceptor response with increasing concentrations of olorinab. (C) Single-unit colonic nociceptor recordings from $\mathrm{CVH}$ mice showed mechanical responsiveness at baseline and dose-dependent inhibition with increasing concentrations of olorinab. (D) Application of the $\mathrm{CB}_{2}$ antagonist SR144528 had no effect on the baseline mechanosensitivity of $\mathrm{CVH}$ colonic nociceptors and prevented olorinab-induced inhibition of nociceptor action potential firing in response to mechanical stimulation (2 $\mathrm{g}$ vfh; $P>0.05)$. (E) The change in $\mathrm{CVH}$ colonic nociceptor mechanosensitivity induced by olorinab compared with baseline demonstrated no inhibitory action of olorinab in the presence of the $\mathrm{CB}_{2}$ antagonist. $(\mathrm{F}$ ) Single-unit colonic nociceptor recordings from $\mathrm{CVH}$ mice showed the mechanical responsiveness was unchanged with olorinab application in the presence of the $\mathrm{CB}_{2}$ antagonist. Data are presented as mean \pm SEM. Statistical analysis was performed using a one-way ANOVA with Bonferroni post hoc tests. ANOVA, analysis of variance; $\mathrm{CB}_{2}$, cannabinoid receptor 2; $\mathrm{CVH}$, colonic visceral hypersensitivity; IBS, irritable bowel syndrome; vfh, von Frey hair. 
A

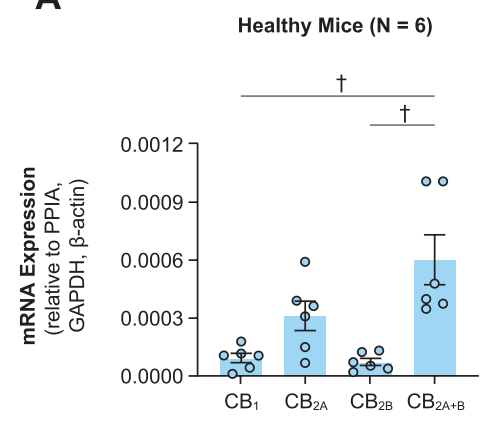

B

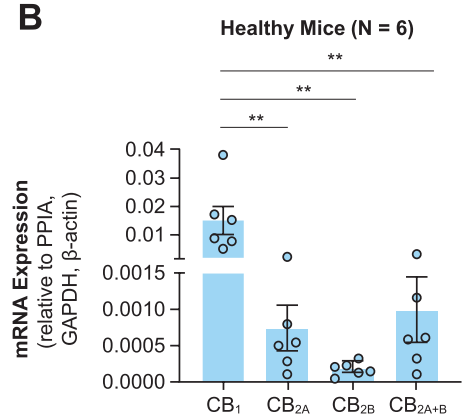

C

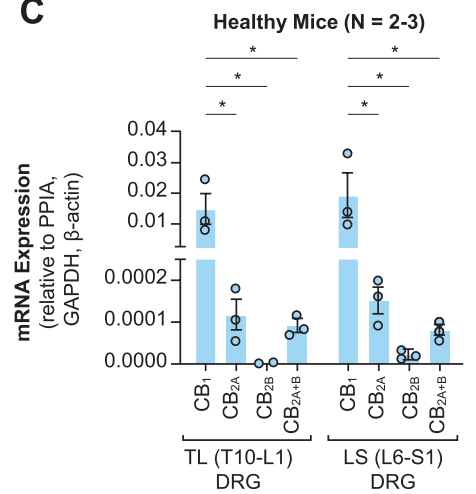

Colonic Mucosa

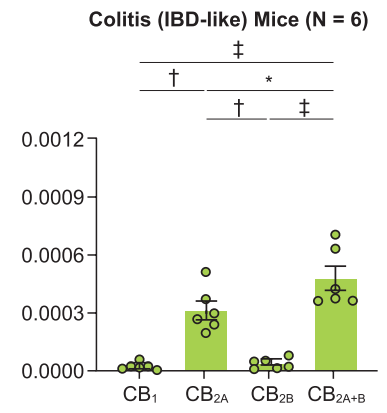

\section{Colonic Muscle + ENS}

Colitis (IBD-like) Mice ( $=6$ )

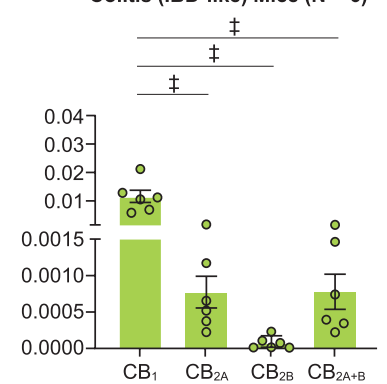

DRG

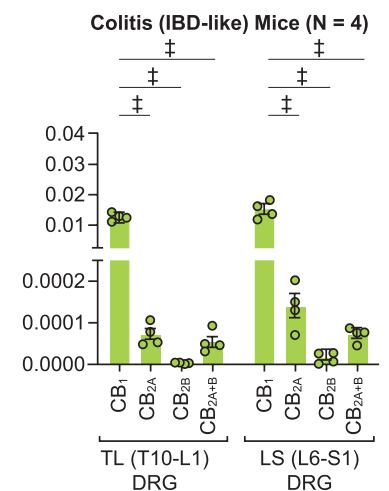

CVH (IBS-like) Mice ( $\mathrm{N}=7$ )

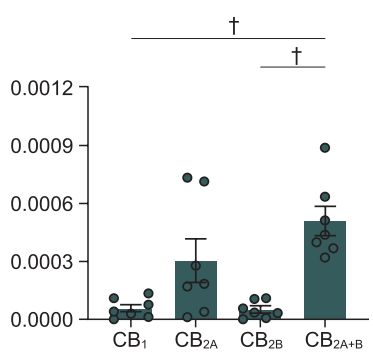

CVH (IBS-like) Mice ( $\mathrm{N}=7$ )

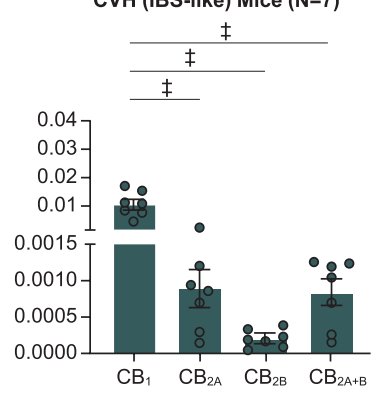

Figure 7. $\mathrm{CB}_{1}$ and $\mathrm{CB}_{2} \mathrm{mRNA}$ expression in tissue from healthy, colitis, and $\mathrm{CVH}$ mice. $(\mathrm{A}) \mathrm{CB}_{2}\left(\mathrm{CB}_{2} \mathrm{~A}+\mathrm{B}\right.$ isoforms) was predominantly expressed over $\mathrm{CB}_{1}$ in the colonic mucosa from healthy, colitis, and $\mathrm{CVH}$ mice, with $\mathrm{CB}_{2 \mathrm{~A}}$ as the most prevalent $\mathrm{CB}_{2}$ isoform. (B) In the colonic longitudinal and circular muscle also containing the myenteric plexus (ENS) from healthy, colitis, and $\mathrm{CVH}$ mice, $\mathrm{CB}_{1}$ had the highest relative abundance of all $\mathrm{CB}$ receptor transcripts compared with $\mathrm{CB}_{2 \mathrm{~A}+\mathrm{B}}, \mathrm{CB}_{2 \mathrm{~A}}$, and $\mathrm{CB}_{2 \mathrm{~B}}$. (C) In TL and LS DRG from healthy, colitis, and CVH mice, $\mathrm{CB}_{1}$ had the highest relative abundance of all $\mathrm{CB}$ receptor transcripts. CB mRNA was also detected in the TL and LS DRG, with the $\mathrm{CB}_{2 \mathrm{~A}}$ isoform as the predominantly expressed $\mathrm{CB}_{2}$ isoform. Expression profiles did not significantly differ between healthy, colitis, and CVH states in the (A) colonic mucosa, (B) colonic muscle + ENS, or (C) TL or LS DRG (P $>0.05)$. All comparisons shown were performed using a one-way ANOVA followed by the Tukey multiple comparison post hoc test ( $\left.{ }^{\star} P<0.05 ;{ }^{\star \star} P<0.01 ;+P<0.001 ; \neq P<0.0001\right)$. $\mathrm{CB}_{1}$ and $\mathrm{CB}_{2}$ mRNA expression was measured relative to reference gene mRNA expression (Ppia, Gapdh, and $\beta$-actin) quantified by geometric mean. Data are presented as mean \pm SEM. ANOVA, analysis of variance; $\mathrm{CB}_{1}$, cannabinoid receptor 1; $\mathrm{CB}_{2}$, cannabinoid receptor 2; DRG, dorsal root ganglia; ENS, enteric nervous system; Gapdh, glyceraldehyde-3-phosphate dehydrogenase; IBD, inflammatory bowel disease; IBS, irritable bowel syndrome; LS, lumbosacral; mRNA, messenger ribonucleic acid; Ppia, peptidylprolyl isomerase $A$; TL, thoracolumbar.

(Figs. 5A-C). Although olorinab treatment did not have a significant effect at a concentration of $0.01 \mu \mathrm{M}$, olorinab at concentrations of $0.1 \mu \mathrm{M}, 1.0 \mu \mathrm{M}$, and $10 \mu \mathrm{M}$ did result in a significant reduction in mechanosensitivity of colonic nociceptors from colitis mice (Figs. 5A-C). To confirm that the antinociceptive effect of olorinab is indeed mediated by $\mathrm{CB}_{2}$, colonic nociceptors from mice with colitis were treated with the $\mathrm{CB}_{2}$ antagonist SR144528 with and without concurrent olorinab administration. SR144528 alone had no effect on the mechanosensitivity of colonic nociceptors from colitis mice, suggesting a lack of endogenous $\mathrm{CB}_{2}$ tone in this state (Figs. 5D-F). However, SR144528 blocked olorinab-induced inhibition of colonic nociceptors from colitis mice (Figs. 5D-F), confirming that $\mathrm{CB}_{2}$ mediates the antinociceptive effect of olorinab in colitis.

To confirm that the antinociceptive effect of olorinab in $\mathrm{CVH}$ states is also mediated by an action on colonic nociceptors, we performed studies similar to those described for colitis mice. Direct application of olorinab to the mucosal surface of colonic nociceptors from $\mathrm{CVH}$ mice resulted in a concentrationdependent reduction in afferent firing to mechanical stimuli 

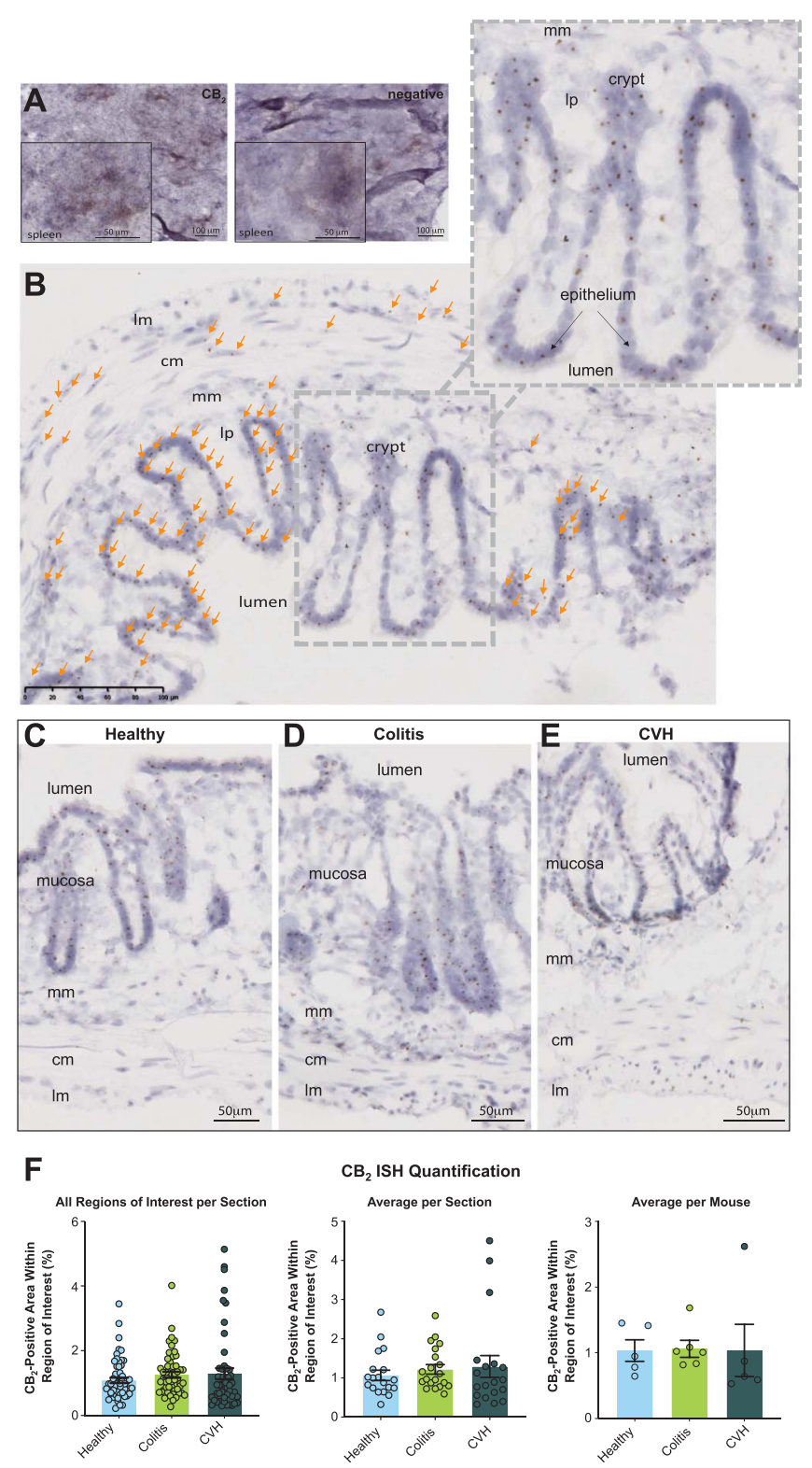

Figure 8. ISH analysis of $\mathrm{CB}_{2}$ mRNA expression in the mouse colon: (A) Positive control tissue for $\mathrm{CB}_{2}$ shows abundant expression of $\mathrm{CB}_{2} \mathrm{mRNA}$ using ISH in cross-sections of the spleen (left panel), whereas the negative control probe (dapB) shows a lack of punctate staining (right panel). (B) $\mathrm{CB}_{2}$ labeling in the colon from a healthy mouse was prominent within epithelial cells lining the lumen edge and crypts (see arrows and inset) with sparser labeling observed in the lamina propria, muscularis mucosae, and myenteric plexus. Representative examples of in situ hybridizations for $\mathrm{CB}_{2}$ on cross-sections of the colon from (C) healthy, (D) colitis, and (E) CVH mice. (F) Quantitative analysis revealed that there was no significant difference in $\mathrm{CB}_{2}$ expression when expressed as $\mathrm{CB}_{2}$-positive area per section (left panel), average $\mathrm{CB}_{2}$-positive area per section (middle panel), or $\mathrm{CB}_{2}$-positive area per mouse (right panel). All comparisons shown were performed using a one-way ANOVA followed by the Tukey multiple comparison post hoc test $(P>0.05)$. Data are presented as mean $\pm \mathrm{SEM}$. $\mathrm{CB}_{2}$, cannabinoid receptor 2 ; $\mathrm{cm}$, circular muscle; $\mathrm{CVH}$, chronic visceral hypersensitivity; dapB, dihydrodipicolinate reductase; ISH, in situ hybridization; Im, Iongitudinal muscle; Ip, lamina propria; LS, lumbosacral; mm, muscularis mucosae; mp, myenteric plexus.

(Figs. 6A-C). A significant reduction in mechanosensitivity was observed with olorinab at concentrations of $0.1 \mu \mathrm{M}, 1.0 \mu \mathrm{M}$, and $10 \mu \mathrm{M}$. Colonic nociceptors from $\mathrm{CVH}$ mice were also treated with the $\mathrm{CB}_{2}$ receptor antagonist SR144528, with and without concurrent olorinab application. SR144528 alone had no effect on the mechanosensitivity of colonic nociceptors from $\mathrm{CVH}$ mice (Figs. 6D-F), suggesting a lack of endogenous $\mathrm{CB}_{2}$ tone in this $\mathrm{CVH}$ state. However, concurrent administration of SR144528 with olorinab attenuated the olorinab-induced reduction in mechanosensitivity of colonic nociceptors from $\mathrm{CVH}$ mice (Figs. 6D-F), confirming that the antinociceptive effect of olorinab in $\mathrm{CVH}$ states is mediated by $\mathrm{CB}_{2}$.

\subsection{Cannabinoid receptor 1 and cannabinoid receptor 2 $m R N A$ expression within colonic tissue and dorsal root ganglia in control, colitis, and chronic visceral hypersensitivity states}

Having shown that olorinab reduced colonic hypersensitivity in colitis and $\mathrm{CVH}$ but not in control states and that this effect was $\mathrm{CB}_{2}$ dependent, we wanted to determine whether $\mathrm{CB}_{2}$ was expressed at potential sites of olorinab activity and to evaluate whether $\mathrm{CB}_{2}$ was upregulated in disease states. To do so, qRT$P C R$ probes for the $2 \mathrm{CB}_{2}$ isoforms $\left(\mathrm{CB}_{2 \mathrm{~A}}\right.$ and $\left.\mathrm{CB}_{2 \mathrm{~B}}\right)$ and a probe that spanned both isoforms $\left(C_{2 A+B}\right)$ were used. $A C_{1}$ probe was also used for comparison. 

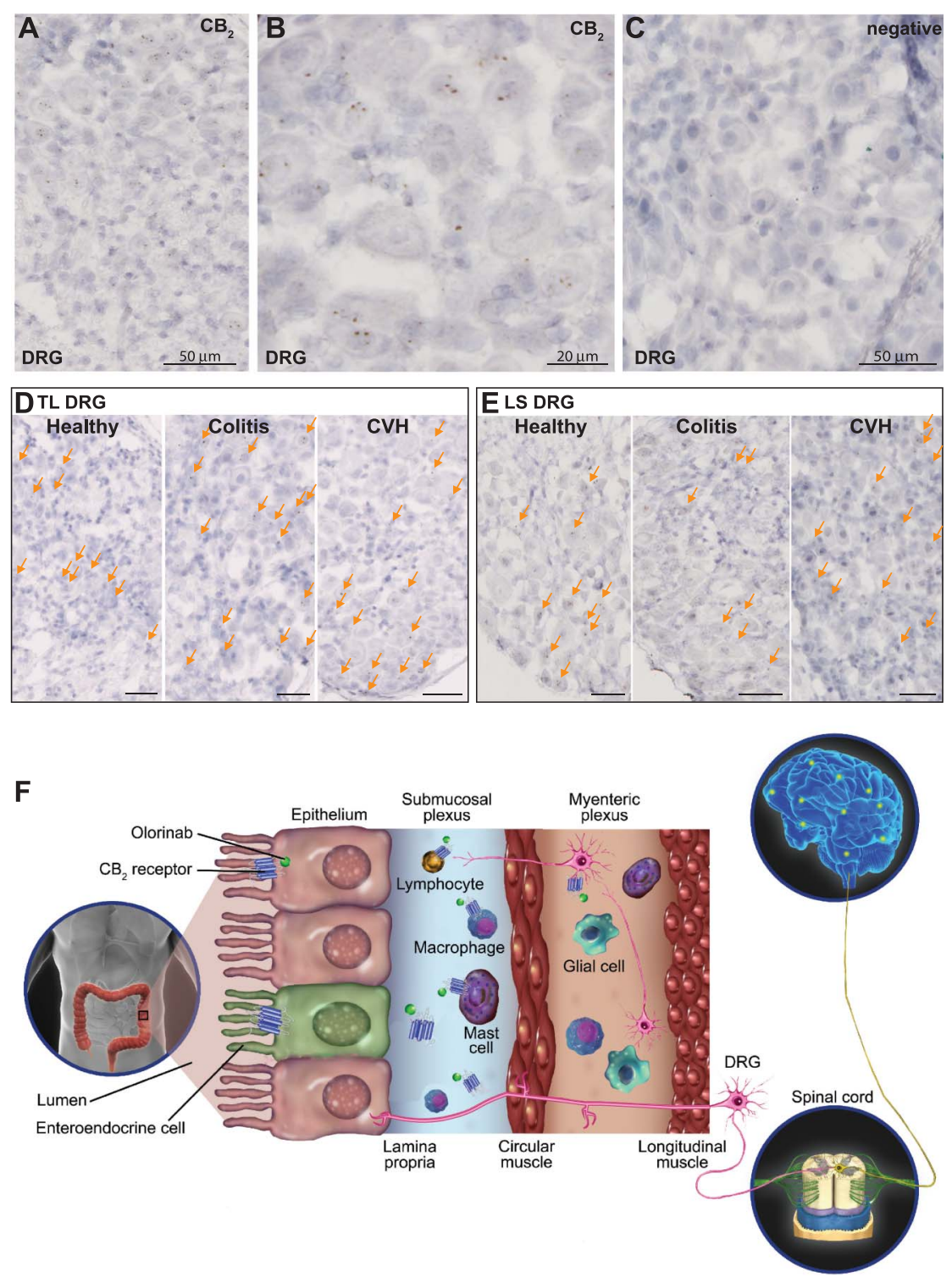

Figure 9. ISH of $\mathrm{CB}_{2}$ mRNA expression in DRG and proposed mechanism of action of olorinab: (A-C) Representative images of sections of thoracolumbar DRG from healthy mice that underwent hematoxylin staining (blue) and ISH labeling for (A, B) $\mathrm{CB}_{2}$ (brown dots) or (C) the negative probe dapB. Representative images of $\mathrm{CB}_{2}$ labeling in sections of (D) thoracolumbar and (E) lumbosacral DRG from healthy, acute colitis, and CVH mice. Scale bars $=20 \mu \mathrm{m}$. (F) Hypothesized mechanism of action of olorinab, which is a highly selective full agonist for $\mathrm{CB}_{2}$ that exhibits low brain penetration. To modulate abdominal pain, olorinab may activate $\mathrm{CB}_{2}$ located on one or multiple cell types including epithelial cells, immune cells, and afferent nerves within the gastrointestinal wall. Downstream or direct effects of $\mathrm{CB}_{2}$ activation may then reduce action potential firing of colonic nociceptors. This would reduce the nociceptive signal being sent from the gastrointestinal tract to the spinal cord, where this nociceptive information is processed and then sent to the brain where pain is perceived. $\mathrm{CB}_{2}$, cannabinoid receptor 2; CVH, chronic visceral hypersensitivity; DRG, dorsal root ganglia; ISH, in situ hybridization; LS, lumbosacral; TL, thoracolumbar.

mRNA expression of $\mathrm{CB}_{1}$ and $\mathrm{CB}_{2}$ was assessed in the colonic mucosa, the circular and longitudinal muscle of the colon including the myenteric plexus between them (colonic muscle + ENS), and DRG isolated from healthy control, colitis, and $\mathrm{CVH}$ mice. We found that $\mathrm{CB}_{2}$ was the more abundant transcript in the colonic mucosa and that there were no significant differences in $\mathrm{CB}_{1}$ or $\mathrm{CB}_{2}$ isoform expression between control, colitis, and $\mathrm{CVH}$ states (Fig. 7A). By contrast, $\mathrm{CB}_{1}$ was the predominant isoform in the colonic muscle + ENS, followed by $\mathrm{CB}_{2 \mathrm{~A}}$ (Fig. 7B). However, no significant differences in $\mathrm{CB}_{1}$ or $\mathrm{CB}_{2}$ expression levels were observed between healthy control, colitis, and $\mathrm{CVH}$ states (Fig. 7B). In the TL and LS DRG that innervate the colon, $\mathrm{CB}_{1}$ was the predominantly expressed cannabinoid receptor, whereas $\mathrm{CB}_{2 \mathrm{~A}}$ was the most abundantly expressed $\mathrm{CB}_{2}$ isoform (Fig. 7C). Overall, there was no significant difference in isoform expression between the DRG in control, colitis, and $\mathrm{CVH}$ states, suggesting a lack of change in transcription of these receptors in the DRG at the time points investigated (Fig. 7C).

\subsection{Cannabinoid receptor 2 mRNA localization using in situ hybridization within colonic tissue and dorsal root ganglia in control, colitis, and chronic visceral hypersensitivity states}

Olorinab reduced visceral hypersensitivity ex vivo and in vivo in colitis and $\mathrm{CVH}$ states but did not significantly change $\mathrm{CB}_{2} \mathrm{mRNA}$ expression, as demonstrated by qRT-PCR. Therefore, we sought to determine the localization of $\mathrm{CB}_{2}$ in colonic tissue and $\mathrm{DRG}$ using $\mathrm{ISH}$. First, the $\mathrm{CB}_{2}$ probe was validated using positive 
control tissue (spleen), which is known to express $\mathrm{CB}_{2}$ (Fig. 8A). In colonic tissue, $\mathrm{CB}_{2}$ labeling was prominent within the epithelial cells lining the lumen and the crypts (Figs. 8B, C). In comparison, $\mathrm{CB}_{2}$ mRNA labeling was sparser within the lamina propria, muscularis mucosae, and myenteric plexus (Figs. 8B, C). Quantitative analysis showed that there was no significant difference in $\mathrm{CB}_{2}$ expression in the colons from healthy, colitis, and CVH mice (Figs. 8C-F). We also performed ISH in TL and LS $D R G$ and found that $C_{2}$ mRNA localized in subsets of DRG neurons from healthy control, colitis, and CVH mice (Figs. 9A-E).

\section{Discussion}

Visceral hypersensitivity associated with colitis leads to substantial abdominal pain in patients with IBD. Colitis results in the release of neuroactive signaling molecules from a variety of cell types, including epithelial and immune cells. ${ }^{7,23}$ Numerous mediators can act directly on receptors expressed by afferent fibers innervating the colon, resulting in sensitization to mechanical and chemical stimuli. 23,50 Importantly, activation of nociceptors can induce an inflammatory reaction (neurogenic inflammation) by releasing calcitonin generelated peptide and substance $P$ from their peripheral terminals, ${ }^{7,23}$ further increasing afferent sensitization. Similarly, visceral hypersensitivity is a key mechanism underlying abdominal pain in IBS and may result from increased intestinal permeability, altered gut microbiota, low-grade inflammation, and dysfunction of the brain-gut axis. $^{7,10,21,23}$ Therefore, reducing visceral hypersensitivity is a targeted way to potentially alleviate abdominal pain in IBD and IBS.

In our study, intracolonic administration of TNBS or DNBS was used to induce colitis resulting in significantly enhanced VMR to $\mathrm{CRD}$ and colonic nociceptor activity compared with control animals, consistent with the induction of visceral hypersensitivity. Similarly, in the postinflammatory state, we observed CVH in ex vivo and in vivo studies. These observations are comparable with previous reports demonstrating inflammation-induced hypersensitivity of colonic afferents at acute and chronic time points. ${ }^{1,11-13,15,17,24,31,32,35,49}$ These findings support the validity of these preclinical models for the evaluation of the role of $\mathrm{CB}_{2}$ signaling in colitis-induced acute and chronic visceral pain. $1,7,17,23,24,32$

Olorinab ( 3 and $30 \mathrm{mg} / \mathrm{kg}$ ) significantly reduced the VMR to CRD in colitis rodents compared with vehicle treatment. In the presence of olorinab, VMR to CRD in animals with colitis was similar to responses in healthy control animals, and no effects on colonic compliance in any treatment group were observed. Furthermore, mechanosensory responses of colonic nociceptors were significantly and dose dependently reduced with olorinab in colitis animals. We found similar results in our $\mathrm{CVH}$ model when mice were administered olorinab at a time point when visceral hypersensitivity was already established. We extended these studies in $\mathrm{CVH}$ mice to include additional doses of olorinab and found that 3,10 , and $30 \mathrm{mg} / \mathrm{kg}$ reduced visceral hypersensitivity in vivo. In addition, mechanosensory responses of colonic nociceptors from $\mathrm{CVH}$ mice were significantly and dose dependently reduced by olorinab. In colitis and $\mathrm{CVH}$ states, the antinociceptive activity of olorinab was blocked by the $\mathrm{CB}_{2}$ antagonist $\mathrm{SR} 144528$.

Our data support a previous study using VMR to CRD in rodents with colitis induced by TNBS to assess the relative roles of $\mathrm{CB}_{1}$ and $\mathrm{CB}_{2} .{ }^{52}$ Agonists of both $\mathrm{CB}_{1}$ and $\mathrm{CB}_{2}$ have been shown to diminish the hypersensitivity caused by colitis, and a $\mathrm{CB}_{1}$ antagonist could enhance colitis-induced hyperalgesia. ${ }^{52}$ Similar protective effects of $\mathrm{CB}_{2}$ activation in preclinical models of colitis have been shown, and these effects were blocked in the presence of a $\mathrm{CB}_{2}$ antagonist and were absent in $\mathrm{CB}_{2}$-deficient mice. ${ }^{57}$ Therefore, the results of this study provide additional support for the role of $\mathrm{CB}_{2}$ in reducing visceral nociception during and after colitis and the specificity of olorinab in targeting $\mathrm{CB}_{2}$.

Our data are also in line with previous observations that $\mathrm{CB}_{2}$ activation is an important regulator of neuroimmune function in small intestinal nerves. ${ }^{28}$ Bradykinin-induced activation of mesenteric afferents in vivo was reversed by the selective $\mathrm{CB}_{2}$ agonist AM1241, and this effect was completely abolished by the $\mathrm{CB}_{2}$ antagonist AM630. ${ }^{28}$ Notably, Hillsley and colleagues showed that AM1241 also inhibited bradykinin effects in mesenteric afferents from healthy unsensitized animals, ${ }^{28}$ whereas in our study, $\mathrm{CB}_{2}$ activation with olorinab had no impact on VMR to $\mathrm{CRD}$ or mechanosensitive nociceptors in tissue from healthy animals. Key differences between our study and this previously published work include ex vivo recordings from colonic afferents vs in vivo recordings from small intestinal afferents, as well as comparing the effects of $\mathrm{CB}_{2}$ agonists on mechanical vs chemical (bradykinin) stimulation of afferents. In addition, not all $\mathrm{CB}_{2}$ agonists activate $\mathrm{CB}_{2}$ in the same manner, with various agonists showing bias for different signal transduction pathways ${ }^{55}$; therefore, $\mathrm{AM} 1241$ and olorinab may interact with $\mathrm{CB}_{2}$ differently resulting in these observations. Furthermore, olorinab is a full agonist of $\mathrm{CB}_{2}$, which is critical for efficient receptor internalization and prevention of tachyphylaxis, ${ }^{2,26}$ whereas AM1241 acts as a partial $\mathrm{CB}_{2}$ agonist, ${ }^{62}$ which may also contribute to these differences. Moreover, our previous research has identified other G-protein-coupled receptors that appear nonfunctional or dormant in healthy conditions but become responsive to selective agonists in disease states. ${ }^{8,17,32}$ This functional upregulation was observed with $\mathrm{k}$-opioid receptors $(\mathrm{KORs})^{8,32}$ and oxytocin receptors (OTRs), ${ }^{17}$ which only mediated antinociceptive effects in colonic nociceptors during colitis or postinflammatory $\mathrm{CVH}$ states, but not during healthy states. ${ }^{8,17,32}$ Transcriptional and/or posttranscriptional modifications may contribute to these observations; however, more studies are needed to understand the molecular mechanisms accounting for the functional upregulation of KORs, OTRs, and $\mathrm{CB}_{2}$ in diseased states.

Using qRT-PCR, we observed low but detectable levels of $\mathrm{CB}_{2}$ mRNA in the DRG of healthy, colitis, and CVH animals. We also showed that $\mathrm{CB}_{2}$ mRNA is expressed within the colonic mucosa and colonic muscle + ENS in healthy, colitis, and CVH states. Interestingly, although $\mathrm{CB}_{1}$ is expressed at higher abundance than $\mathrm{CB}_{2}$ in the DRG and colonic muscle + ENS, in the colonic mucosa, $\mathrm{CB}_{2}$-specifically the $\mathrm{CB}_{2 \mathrm{~A}}$ isoform-predominates. These findings confirm $\mathrm{CB}_{2}$ expression patterns observed in previous studies. ${ }^{20,43,60}$ Our ISH studies further confirm these observations, with $\mathrm{CB}_{2}$ mRNA predominantly localized in colonic epithelial cells and some expression also observed in the lamina propria, muscularis mucosae, myenteric plexus, and subsets of neurons in the TL and LS DRG. This localization in DRG neurons confirms previous RNAseq analysis, indicating that some coloninnervating DRG neurons express $\mathrm{CB}_{2}$ mRNA. ${ }^{29}$

Although previous work has shown increased expression of $\mathrm{CB}_{2}$ in preclinical models of gastrointestinal inflammation and disease ${ }^{39,57}$ and in colonic tissue from patients with IBD $^{60}$ and $\mathrm{IBS}^{16,19}$ compared with healthy individuals, a significant increase in $\mathrm{CB}_{2}$ mRNA expression was not observed in colitis or $\mathrm{CVH}$ vs healthy states in the tissues investigated in our study. The lack of change in $\mathrm{CB}_{2}$ mRNA expression in colonic tissue in colitis or $\mathrm{CVH}$ mice we observed is consistent with other studies using a DNBS-induced colitis mouse model. ${ }^{5}$ Overall, these differences may be due to several factors. For example, $\mathrm{CB}_{2}$ expression was assessed at very specific time 
points in the colitis and $\mathrm{CVH}$ profile when colonic hypersensitivity is known to be present. However, the kinetics of $\mathrm{CB}_{2}$ transcript upregulation in these acute $\mathrm{VH}$ and $\mathrm{CVH}$ rodent models may differ from other models or the longer-term chronic disease states associated with IBD and IBS. Overall, our current findings suggest $\mathrm{CB}_{2}$ expression is not dramatically upregulated after an inflammatory trigger, as seen with OTRs. Rather, $\mathrm{CB}_{2}$ appears to lie in a dormant state until it is sensitized, much like our previous findings with KORs. ${ }^{8,32}$

In addition to promoting antinociceptive effects on colonic afferents, $\mathrm{CB}_{2}$ agonism has been reported to reduce inflammation in models of IBD. ${ }^{28,39,52,54,57}$ Activation of $\mathrm{CB}_{2}$ expressed on immune cells results in changes in the cytokine profile secreted, ${ }^{37,39,58}$ which can lead to the modulation of inflammation and can potentially reduce neuronal sensitization. ${ }^{23,39,50,54}$ This is further supported by increased susceptibility to TNBSinduced colitis and inflammation in $\mathrm{CB}_{2}$-knockout mice compared with wild-type mice. ${ }^{22}$ Furthermore, research using human explant tissue has shown that activation of $\mathrm{CB}_{2}$, but not $\mathrm{CB}_{1}$, may protect against cytokine-mediated inflammation and epithelial damage known to contribute to abdominal pain. ${ }^{27}$ Future studies will investigate whether olorinab has potential anti-inflammatory actions that may mediate or contribute to its antinociceptive actions.

Overall, these data indicate that olorinab, through selective activation of $\mathrm{CB}_{2}$, may provide a novel treatment for abdominal pain associated with IBD and IBS. These data provide further evidence of $\mathrm{CB}_{2}$-mediated control of visceral hypersensitivity during or after states of inflammation and increased function of $\mathrm{CB}_{2}$ in diseased states. We hypothesize that olorinab might activate $\mathrm{CB}_{2}$ located on one or multiple cell types, including epithelial cells, immune cells, and nerves in the intestinal wall (Fig. 9F). After receptor activation, direct or indirect effects of $\mathrm{CB}_{2}$ activation may then suppress colonic nociceptors sending nociceptive signals to the central nervous system. It should be noted that although these data are derived from well-studied and validated rodent models of colitis and $\mathrm{CVH}$, as in all animal models, there is no certainty that the model accurately reflects human disease in all conditions.

In conclusion, our data indicate that olorinab, a selective full $\mathrm{CB}_{2}$ agonist, was effective at reducing visceral hypersensitivity in animal models of IBD and IBS. These preclinical data exploring the mechanism of action and impact of olorinab on visceral hypersensitivity support the further evaluation of olorinab in clinical settings. Olorinab is currently in clinical development for abdominal pain associated with gastrointestinal conditions, including IBD (Clinicaltrials.gov identifier, NCT03155945) and IBS (NCT04043455).

\section{Conflict of interest statement}

S. Schmiel, B. Lindstrom, and J. Adams are employees of Arena Pharmaceuticals, Inc. S.M. Brierley received research funding from Arena Pharmaceuticals to conduct the study. The remaining authors have no conflicts of interest to declare. Data from this study were previously presented in part at Digestive Disease Week (DDW) on May 2, 2020, as a virtual ePoster; DDW 2019 on May 18 to 21, 2019, in San Diego, CA; American Neurogastroenterology and Motility Society (ANMS) Annual Meeting on August 16 to 18, 2019, in Chicago, IL; United European Gastroenterology (UEG) Week on October 11, 2020, as a virtual presentation; and UEGW on October 19 to 23, 2019, in Barcelona, Spain.

\section{Acknowledgments}

Medical writing support was provided by ApotheCom (San Francisco, CA) and was funded by Arena Pharmaceuticals. S.M. Brierley was supported by a National Health and Medical Research Council of Australia (NHMRC) R.D. Wright Biomedical Research Fellowship (APP1126378) and by NHMRC Australia Project Grants (APP1139366 and APP1140297). J. Castro is funded by an NHMRC Australia Ideas Grant (APP1181448). A.M. Harrington is funded by an ARC Discovery Project (DP180101395).

\section{Article history:}

Received 19 October 2020

Received in revised form 12 March 2021

Accepted 2 April 2021

Available online 13 April 2021

\section{References}

[1] Adam B, Liebregts T, Gschossmann JM, Krippner C, Scholl F, Ruwe M, Holtmann G. Severity of mucosal inflammation as a predictor for alterations of visceral sensory function in a rat model. PAIN 2006;123: 179-86.

[2] Adams JW, Unett D, Anthony T, Gaitlin J, Gaidarov I. APD371: a Potent, highly selective, full agonist of the human $\mathrm{CB} 2$ receptor with sustained analgesic effects in rodents. J Pain 2018;19(S2).

[3] American Gastroenterological Association. IBS in America. Survey summary findings. Vol. 2020. Bethesda, MD: American Gastroenterological Association, 2015.

[4] Bellono NW, Bayrer JR, Leitch DB, Castro J, Zhang C, O'Donnell TA, Brierley SM, Ingraham HA, Julius D. Enterochromaffin cells are gut chemosensors that couple to sensory neural pathways. Cell 2017;170: 185-98.e116.

[5] Borrelli F, Romano B, Petrosino S, Pagano E, Capasso R, Coppola D, Battista G, Orlando P, Di Marzo V, Izzo AA. Palmitoylethanolamide, a naturally occurring lipid, is an orally effective intestinal anti-inflammatory agent. Br J Pharmacol 2015;172:142-58.

[6] Brierley SM, Jones RC III, Gebhart GF, Blackshaw LA. Splanchnic and pelvic mechanosensory afferents signal different qualities of colonic stimuli in mice. Gastroenterology 2004;127:166-78.

[7] Brierley SM, Linden DR. Neuroplasticity and dysfunction after gastrointestinal inflammation. Nat Rev Gastroenterol Hepatol 2014;11: 611-27.

[8] Brust A, Croker DE, Colless B, Ragnarsson L, Andersson A, Jain K, Garcia-Caraballo S, Castro J, Brierley SM, Alewood PF, Lewis RJ. Conopeptide-derived kappa-opioid agonists (conorphins): potent, selective, and metabolic stable dynorphin a mimetics with antinociceptive properties. J Med Chem 2016;59:2381-95.

[9] Cain KC, Headstrom P, Jarrett ME, Motzer SA, Park H, Burr RL, Surawicz $\mathrm{CM}$, Heitkemper MM. Abdominal pain impacts quality of life in women with irritable bowel syndrome. Am J Gastroenterol 2006;101:124-32.

[10] Camilleri M. Physiological underpinnings of irritable bowel syndrome: neurohormonal mechanisms. J Physiol 2014;592:2967-80.

[11] Carstens BB, Berecki G, Daniel JT, Lee HS, Jackson KA, Tae HS, Sadeghi M, Castro J, O'Donnell T, Deiteren A, Brierley SM, Craik DJ, Adams DJ, Clark RJ. Structure-activity studies of cysteine-rich alphaconotoxins that inhibit high-voltage-activated calcium channels via GABA(B) receptor activation reveal a minimal functional motif. Angew Chem Int Ed Engl 2016;55:4692-6.

[12] Castro J, Grundy L, Deiteren A, Harrington AM, O'Donnell T, Maddern J, Moore J, Garcia-Caraballo S, Rychkov GY, Yu R, Kaas Q, Craik DJ, Adams DJ, Brierley SM. Cyclic analogues of alpha-conotoxin Vc1.1 inhibit colonic nociceptors and provide analgesia in a mouse model of chronic abdominal pain. Br J Pharmacol 2018;175:2384-98.

[13] Castro J, Harrington AM, Garcia-Caraballo S, Maddern J, Grundy L, Zhang J, Page G, Miller PE, Craik DJ, Adams DJ, Brierley SM. alphaConotoxin Vc1.1 inhibits human dorsal root ganglion neuroexcitability and mouse colonic nociception via GABAB receptors. Gut 2017;66: 1083-94.

[14] Castro J, Harrington AM, Hughes PA, Martin CM, Ge P, Shea CM, Jin H, Jacobson S, Hannig G, Mann E, Cohen MB, MacDougall JE, Lavins BJ, Kurtz CB, Silos-Santiago I, Johnston JM, Currie MG, Blackshaw LA, Brierley SM. Linaclotide inhibits colonic nociceptors and relieves 
abdominal pain via guanylate cyclase- $\mathrm{C}$ and extracellular cyclic guanosine 3',5'-monophosphate. Gastroenterology 2013;145: 1334-6.e1331-1311.

[15] Castro J, Harrington AM, Lieu T, Garcia-Caraballo S, Maddern J, Schober G, O'Donnell T, Grundy L, Lumsden AL, Miller P, Ghetti A, Steinhoff MS, Poole DP, Dong X, Chang L, Bunnett NW, Brierley SM. Activation of pruritogenic TGR5, MrgprA3, and MrgprC11 on coloninnervating afferents induces visceral hypersensitivity. JCl Insight 2019;4: e131712.

[16] Cremon C, Stanghellini V, Barbaro MR, Cogliandro RF, Bellacosa L, Santos J, Vicario M, Pigrau M, Alonso Cotoner C, Lobo B, Azpiroz F, Bruley des Varannes S, Neunlist M, DeFilippis D, luvone T, Petrosino S, Di Marzo V, Barbara G. Randomised clinical trial: the analgesic properties of dietary supplementation with palmitoylethanolamide and polydatin in irritable bowel syndrome. Aliment Pharmacol Ther 2017;45:909-22.

[17] de Araujo AD, Mobli M, Castro J, Harrington AM, Vetter I, Dekan Z, Muttenthaler M, Wan J, Lewis RJ, King GF, Brierley SM, Alewood PF. Selenoether oxytocin analogues have analgesic properties in a mouse model of chronic abdominal pain. Nat Commun 2014;5:3165.

[18] Desormeaux C, Bautzova T, Garcia-Caraballo S, Rolland C, Barbaro MR, Brierley SM, Barbara G, Vergnolle N, Cenac N. Protease-activated receptor 1 is implicated in irritable bowel syndrome mediators-induced signaling to thoracic human sensory neurons. PAIN 2018;159:1257-67.

[19] Dothel G, Chang L, Shih W, Barbaro MR, Cremon C, Stanghellini V, De Ponti F, Mayer EA, Barbara G, Sternini C. micro-opioid receptor, betaendorphin, and cannabinoid receptor-2 are increased in the colonic mucosa of irritable bowel syndrome patients. Neurogastroenterol Motil 2019;31:e13688.

[20] Duncan M, Mouihate A, Mackie K, Keenan CM, Buckley NE, Davison JS, Patel KD, Pittman QJ, Sharkey KA. Cannabinoid CB2 receptors in the enteric nervous system modulate gastrointestinal contractility in lipopolysaccharide-treated rats. Am J Physiol Gastrointest Liver Physiol 2008;295:G78-87.

[21] Enck P, Aziz Q, Barbara G, Farmer AD, Fukudo S, Mayer EA, Niesler B, Quigley EM, Rajilic-Stojanovic M, Schemann M, Schwille-Kiuntke J, Simren M, Zipfel S, Spiller RC. Irritable bowel syndrome. Nat Rev Dis Primers 2016;2:16014.

[22] Engel MA, Kellermann CA, Burnat G, Hahn EG, Rau T, Konturek PC. Mice lacking cannabinoid CB1-, CB2-receptors or both receptors show increased susceptibility to trinitrobenzene sulfonic acid (TNBS)-induced colitis. J Physiol Pharmacol 2010;61:89-97.

[23] Grundy L, Erickson A, Brierley SM. Visceral pain. Annu Rev Physiol 2019; 81:261-84.

[24] Grundy L, Harrington AM, Castro J, Garcia-Caraballo S, Deiteren A, Maddern J, Rychkov GY, Ge P, Peters S, Feil R, Miller P, Ghetti A, Hannig G, Kurtz CB, Silos-Santiago I, Brierley SM. Chronic linaclotide treatment reduces colitis-induced neuroplasticity and reverses persistent bladder dysfunction. JCl Insight 2018;3:e121841.

[25] Han S, Thatte J, Buzard DJ, Jones RM. Therapeutic utility of cannabinoid receptor type 2 (CB(2)) selective agonists. J Med Chem 2013;56: 8224-56.

[26] Han S, Thoresen L, Jung JK, Zhu X, Thatte J, Solomon M, Gaidarov I, Unett DJ, Yoon WH, Barden J, Sadeque A, Usmani A, Chen C, Semple G, Grottick AJ, Al-Shamma H, Christopher R, Jones RM. Discovery of APD371: identification of a highly potent and selective CB2 agonist for the treatment of chronic pain. ACS Med Chem Lett 2017;8:1309-13.

[27] Harvey BS, Nicotra LL, Vu M, Smid SD. Cannabinoid CB2 receptor activation attenuates cytokine-evoked mucosal damage in a human colonic explant model without changing epithelial permeability. Cytokine 2013;63:209-17.

[28] Hillsley K, McCaul C, Aerssens J, Peeters PJ, Gijsen H, Moechars D, Coulie B, Grundy D, Stead RH. Activation of the cannabinoid 2 (CB2) receptor inhibits murine mesenteric afferent nerve activity. Neurogastroenterol Motil 2007;19:769-77.

[29] Hockley JRF, Taylor TS, Callejo G, Wilbrey AL, Gutteridge A, Bach K, Winchester WJ, Bulmer DC, McMurray G, Smith ESJ. Single-cell RNAseq reveals seven classes of colonic sensory neuron. Gut 2019;68:633-44.

[30] Hua T, Li X, Wu L, lliopoulos-Tsoutsouvas C, Wang Y, Wu M, Shen L, Johnston CA, Nikas SP, Song F, Song X, Yuan S, Sun Q, Wu Y, Jiang S, Grim TW, Benchama O, Stahl EL, Zvonok N, Zhao S, Bohn LM, Makriyannis A, Liu ZJ. Activation and signaling mechanism revealed by cannabinoid receptor-gi complex structures. Cell 2020;180:655-65 e618.

[31] Hughes PA, Brierley SM, Martin CM, Brookes SJ, Linden DR, Blackshaw LA. Post-inflammatory colonic afferent sensitisation: different subtypes, different pathways and different time courses. Gut 2009;58:1333-41.
[32] Hughes PA, Castro J, Harrington AM, Isaacs N, Moretta M, Hicks GA, Urso DM, Brierley SM. Increased kappa-opioid receptor expression and function during chronic visceral hypersensitivity. Gut 2014;63:1199-200.

[33] Inserra MC, Israel MR, Caldwell A, Castro J, Deuis JR, Harrington AM, Keramidas A, Garcia-Caraballo S, Maddern J, Erickson A, Grundy L, Rychkov GY, Zimmermann K, Lewis RJ, Brierley SM, Vetter I. Multiple sodium channel isoforms mediate the pathological effects of Pacific ciguatoxin-1. Sci Rep 2017;7:42810.

[34] Iwata Y, Ando K, Taniguchi K, Koba N, Sugiura A, Sudo M. Identification of a highly potent and selective CB2 agonist, RQ-00202730, for the treatment of irritable bowel syndrome. Bioorg Med Chem Lett 2015;25: 236-40.

[35] Jimenez-Vargas NN, Pattison LA, Zhao P, Lieu T, Latorre R, Jensen DD, Castro J, Aurelio L, Le GT, Flynn B, Herenbrink CK, Yeatman HR, Edgington-Mitchell L, Porter CJH, Halls ML, Canals M, Veldhuis NA, Poole DP, McLean P, Hicks GA, Scheff N, Chen E, Bhattacharya A, Schmidt BL, Brierley SM, Vanner SJ, Bunnett NW. Proteaseactivated receptor-2 in endosomes signals persistent pain of irritable bowel syndrome. Proc Natl Acad Sci U S A 2018;115: E7438-47.

[36] Kikuchi A, Ohashi K, Sugie Y, Sugimoto H, Omura H. Pharmacological evaluation of a novel cannabinoid 2 (CB2) ligand, PF-03550096, in vitro and in vivo by using a rat model of visceral hypersensitivity. J Pharmacol Sci 2008;106:219-24.

[37] Kimball ES, Schneider CR, Wallace NH, Hornby PJ. Agonists of cannabinoid receptor 1 and 2 inhibit experimental colitis induced by oil of mustard and by dextran sulfate sodium. Am J Physiol Gastrointest Liver Physiol 2006;291:G364-71.

[38] Krishna Kumar K, Shalev-Benami M, Robertson MJ, Hu H, Banister SD, Hollingsworth SA, Latorraca NR, Kato HE, Hilger D, Maeda S, Weis WI, Farrens DL, Dror RO, Malhotra SV, Kobilka BK, Skiniotis G. Structure of a signaling cannabinoid receptor 1-G protein complex. Cell 2019;176: 448-58.e412.

[39] Leinwand KL, Jones AA, Huang RH, Jedlicka P, Kao DJ, de Zoeten EF, Ghosh S, Moaddel R, Wehkamp J, Ostaff MJ, Bader J, Aherne CM, Collins CB. Cannabinoid receptor-2 ameliorates inflammation in murine model of Crohn's Disease. J Crohns Colitis 2017;11:1369-80.

[40] Li X, Hua T, Vemuri K, Ho JH, Wu Y, Wu L, Popov P, Benchama O, Zvonok N, Locke K, Qu L, Han GW, lyer MR, Cinar R, Coffey NJ, Wang J, Wu M, Katritch V, Zhao S, Kunos G, Bohn LM, Makriyannis A, Stevens RC, Liu ZJ. Crystal structure of the human cannabinoid receptor CB2. Cell 2019;176:459-67.e413.

[41] Liu QR, Pan CH, Hishimoto A, Li CY, Xi ZX, Llorente-Berzal A, Viveros MP, Ishiguro $H$, Arinami T, Onaivi ES, Uhl GR. Species differences in cannabinoid receptor 2 (CNR2 gene): identification of novel human and rodent CB2 isoforms, differential tissue expression and regulation by cannabinoid receptor ligands. Genes Brain Behav 2009;8:519-30.

[42] Mearin F, Lacy BE, Chang L, Chey WD, Lembo AJ, Simren M, Spiller R. Bowel disorders. Gastroenterology 2016;S0016-5085:00222-5.

[43] Merriam FV, Wang ZY, Guerios SD, Bjorling DE. Cannabinoid receptor 2 is increased in acutely and chronically inflamed bladder of rats. Neurosci Lett 2008;445:130-4.

[44] Moayyedi P, Mearin F, Azpiroz F, Andresen V, Barbara G, Corsetti M, Emmanuel A, Hungin APS, Layer P, Stanghellini V, Whorwell P, Zerbib F, Tack J. Irritable bowel syndrome diagnosis and management: a simplified algorithm for clinical practice. United Eur Gastroenterol J 2017;5:773-88.

[45] Moreira FA, Grieb M, Lutz B. Central side-effects of therapies based on CB1 cannabinoid receptor agonists and antagonists: focus on anxiety and depression. Best Pract Res Clin Endocrinol Metab 2009;23:133-44.

[46] Naguib M, Diaz P, Xu JJ, Astruc-Diaz F, Craig S, Vivas-Mejia P, Brown DL. MDA7: a novel selective agonist for $\mathrm{CB} 2$ receptors that prevents allodynia in rat neuropathic pain models. Br J Pharmacol 2008;155:1104-16.

[47] Ness TJ, Gebhart GF. Colorectal distension as a noxious visceral stimulus: physiologic and pharmacologic characterization of pseudaffective reflexes in the rat. Brain Res 1988;450:153-69.

[48] Ng SC, Shi HY, Hamidi N, Underwood FE, Tang W, Benchimol El, Panaccione R, Ghosh S, Wu JCY, Chan FKL, Sung JJY, Kaplan GG. Worldwide incidence and prevalence of inflammatory bowel disease in the 21st century: a systematic review of population-based studies. Lancet 2018;390:2769-78.

[49] Osteen JD, Herzig V, Gilchrist J, Emrick JJ, Zhang C, Wang X, Castro J, Garcia-Caraballo S, Grundy L, Rychkov GY, Weyer AD, Dekan Z, Undheim EA, Alewood P, Stucky CL, Brierley SM, Basbaum Al, Bosmans F, King GF, Julius D. Selective spider toxins reveal a role for the Nav1.1 channel in mechanical pain. Nature 2016;534:494-9. 
[50] Sadeghi M, Erickson A, Castro J, Deiteren A, Harrington AM, Grundy L, Adams DJ, Brierley SM. Contribution of membrane receptor signalling to chronic visceral pain. Int J Biochem Cell Biol 2018;98:10-23.

[51] Salvatierra J, Castro J, Erickson A, Li Q, Braz J, Gilchrist J, Grundy L, Rychkov GY, Deiteren A, Rais R, King GF, Slusher BS, Basbaum A, Pasricha PJ, Brierley SM, Bosmans F. NaV1.1 inhibition can reduce visceral hypersensitivity. JCl Insight 2018;3:e121000.

[52] Sanson M, Bueno L, Fioramonti J. Involvement of cannabinoid receptors in inflammatory hypersensitivity to colonic distension in rats. Neurogastroenterol Motil 2006;18:949-56.

[53] Sharkey KA, Wiley JW. The role of the endocannabinoid system in the brain-gut axis. Gastroenterology 2016;151:252-66.

[54] Singh UP, Singh NP, Singh B, Price RL, Nagarkatti M, Nagarkatti PS. Cannabinoid receptor-2 (CB2) agonist ameliorates colitis in IL-10(-/-) mice by attenuating the activation of $T$ cells and promoting their apoptosis. Toxicol Appl Pharmacol 2012;258:256-67.

[55] Soethoudt M, Grether U, Fingerle J, Grim TW, Fezza F, de Petrocellis L, Ullmer C, Rothenhausler B, Perret C, van Gils N, Finlay D, MacDonald C, Chicca A, Gens MD, Stuart J, de Vries H, Mastrangelo N, Xia L, Alachouzos G, Baggelaar MP, Martella A, Mock ED, Deng H, Heitman LH, Connor M, Di Marzo V, Gertsch J, Lichtman AH, Maccarrone M, Pacher P, Glass M, van der Stelt M. Cannabinoid CB2 receptor ligand profiling reveals biased signalling and off-target activity. Nat Commun 2017;8:13958.

[56] Spiegel BM, Bolus R, Harris LA, Lucak S, Chey WD, Sayuk G, Esrailian E, Lembo A, Karsan H, Tillisch K, Talley J, Chang L. Characterizing abdominal pain in IBS: guidance for study inclusion criteria, outcome measurement and clinical practice. Aliment Pharmacol Ther 2010;32:1192-202.

[57] Storr MA, Keenan CM, Zhang H, Patel KD, Makriyannis A, Sharkey KA. Activation of the cannabinoid 2 receptor (CB2) protects against experimental colitis. Inflamm Bowel Dis 2009;15:1678-85.
[58] Turcotte C, Blanchet MR, Laviolette M, Flamand N. The CB(2) receptor and its role as a regulator of inflammation. Cell Mol Life Sci 2016;73: 4449-70.

[59] Weinland SR, Morris CB, Hu Y, Leserman J, Bangdiwala SI, Drossman DA. Characterization of episodes of irritable bowel syndrome using ecological momentary assessment. Am J Gastroenterol 2011;106: 1813-20.

[60] Wright K, Rooney N, Feeney M, Tate J, Robertson D, Welham M, Ward S. Differential expression of cannabinoid receptors in the human colon: cannabinoids promote epithelial wound healing. Gastroenterology 2005; 129:437-53.

[61] Yacyshyn BR, Hanauer S, Klassen P, English BA, Stauber K, Barish CF, Gilder K, Turner S, Higgins PDR. Safety, pharmacokinetics, and efficacy of olorinab, a peripherally acting, highly selective, full agonist of the cannabinoid receptor 2 , in a phase 2 a study of patients with chronic abdominal pain associated with Crohn's disease. Crohn's Colitis 2020; 360:3.

[62] Yao BB, Mukherjee S, Fan Y, Garrison TR, Daza AV, Grayson GK, Hooker BA, Dart MJ, Sullivan JP, Meyer MD. In vitro pharmacological characterization of AM1241: a protean agonist at the cannabinoid CB2 receptor? Br J Pharmacol 2006;149:145-54.

[63] Zeitz J, Ak M, Muller-Mottet S, Scharl S, Biedermann L, Fournier N, Frei P, Pittet V, Scharl M, Fried M, Rogler G, Vavricka S. Pain in IBD patients: very frequent and frequently insufficiently taken into account. PLoS One 2016; 11:e0156666.

[64] Zhang HY, Bi GH, Li X, Li J, Qu H, Zhang SJ, Li CY, Onaivi ES, Gardner EL, Xi ZX, Liu QR. Species differences in cannabinoid receptor 2 and receptor responses to cocaine selfadministration in mice and rats. Neuropsychopharmacology 2015; 40:1037-51. 